\title{
HR Managers' Emotions in Strategic Decision-Making Events: Evidence from Croatia
}

\author{
Marli Gonan Božac and Katarina Kostelić *(D)
}

check for updates

Citation: Gonan Božac, M.; Kostelić, K. HR Managers' Emotions in Strategic Decision-Making Events: Evidence from Croatia. Sustainability 2021, 13, 845. https://doi.org/10.3390/ su13020845

Received: 15 December 2020

Accepted: 13 January 2021

Published: 16 January 2021

Publisher's Note: MDPI stays neutral with regard to jurisdictional claims in published maps and institutional affiliations.

Copyright: (c) 2021 by the authors. Licensee MDPI, Basel, Switzerland. This article is an open access article distributed under the terms and conditions of the Creative Commons Attribution (CC BY) license (https:// creativecommons.org/licenses/by/ $4.0 /)$.
Faculty of Economics and Tourism "Dr. Mijo Mirkovic", Juraj Dobrila University of Pula, 52100 Pula, Croatia; marli.gonan.bozac@unipu.hr

* Correspondence: katarina.kostelic@unipu.hr

\begin{abstract}
The inclusion of emotions in the strategic decision-making research is long overdue. This paper deals with the emotions that human resource managers experience when they participate in a strategic problem-solving event or a strategic planning event. We examine the patterns in the intensity of experienced emotions with regard to event appraisal (from a personal perspective and the organization's perspective), job satisfaction, and coexistence of emotions. The results reveal that enthusiasm is the most intensely experienced emotion for positively appraised strategic decision-making events, while frustration is the most intensely experienced emotion for negatively appraised problem-solving events, as is disappointment for strategic planning. The distinction between a personal and organizational perspective of the event appraisal reveals differences in experienced emotions, and the intensity of experienced anger is the best indicator of the difference in the event appraisals from the personal and organizational perspective. Both events reveal the variety of involved emotions and the coexistence of-not just various emotions, but also emotions of different dominant valence. The findings indicate that a strategic problem-solving event triggers greater emotional turmoil than a strategic planning event. The paper also discusses theoretical and practical implications.
\end{abstract}

Keywords: human resource managers; emotions; event appraisal; strategic decision-making

\section{Introduction}

The dynamics of the market, rising competition, and globalization processes, as well as current pandemic and consequential economic crisis, force companies to adjust to changing conditions on a regular basis. Such requirements are even more required for companies in developing countries, especially those which faced transition from closed to open economy. For them, additional challenges arise from the changeability of legal framework, as the government administrations also catch up with the global trends. Whatever challenges organizations face, most of them rely on their employees to carry out the necessary workload. The labor market's dynamics and changes in employees' preferences, along with the changes in the business environment put human resource managers under the spotlight, setting a new requirement for a change in practices [1]. Changes almost always require strategic decisions. The events of strategic decision-making differ from the work events given their frequency, magnitude of consequences, and the length of effects. However, it can be assumed that the strategic decision-making events involve emotions, as they are specific work-related events. Moreover, as strategic decision-making may signify changes, emotions may serve as a vital part, structuring the meaning of change [2]. However, the research on emotions related to strategic decision-making events is scarce, and the research on involved managers and key persons even more so [3,4]. The framework management of change, which is more thoroughly researched, is necessarily related to strategic decision-making events, but it is focused on the implementation and primarily examines employees. Given that employees' emotions have been heavily researched over the last three decades $[5,6]$, it makes sense to expand the research to managers. Starting 
this expansion with human resource (HR) managers seem as a logical next step, given their functional proximity to employees.

HR managers are responsible for planning "human resource deployments and activities intended to enable an organization to achieve its goals" [7], usually applying practices of selection, training/learning, performance management, incentives/rewards, and employee voice [8]. Given their function and their hierarchical position in organizations HR managers are involved in the business strategy formulation, as well as the implementation of those strategies by managing the HR capital pool to achieve targeted HR behavior, contribute to firm sustainability, and ultimately the measurable firm-level outcome [7]. HR managers' positions usually imply top management functions, but their role in strategic decision-making puts them in a position where they have to meet the requirements from both superiors (or organization-level goals) and employees. HR managers emotional expressions could be important because employees interpret these expressions as important stimuli. The experienced emotions in such events are important in terms of health consequences [9,10], emotion crossover [11-13], communication [14,15], performance [16], strategy implementation [17], and organization sustainability [18-22].

The purpose of this research is to examine the occurrence of emotions in two types of strategic decision-making events (as affective events): solving a strategic problem and strategic planning; building on the affective events theory [2,9]. Previous research showed that emotions that occur during the change can be related to both managers' personal interests and organizational triggers [3,17]. Pfister and Böhm [23] propose that "all emotional construals focus on the fundamental relationship between the self and the event, that is, on the relevance a particular event has on a person's vital concerns and interests." Thus, both personal and organizational welfare (in the broadest sense) can be of person's concern and interest and hence, trigger emotions. Inspired by those insights, we also explore the perceived intensity of the experienced emotions and examine whether significant differences in emotions occur given the event appraisal. Building on the affective events theory, we propose that a strategic decision-making event may be classified as positive, negative, or neutral, and this can be done from a personal perspective and from the perspective of an organization. It is important to notice the difference: an event that can ultimately be positive for the company, but it might have been a dreadful personal experience for the involved manager and a negative event from his/her personal point of view; or an event of strategic decision-making might be negative for the company, but a valuable experience and classified as positive from the manager's point of view. Such distinction offers an empirical explanation for revealed coexistence of emotions of both positive and negative valence [3,17]. While the event itself may be observed as composed of elements, we propose that some amount of utility or a certain valence may be more easily assigned to an event (even as a set of elements) than to an emotion.

With an emphasis on HR managers and strategic events, we take a step toward filling in the gaps in research: (1) From the perspective of strategic decision-making, which mainly focuses on the rational perspective where is expected that problem-solving process ends with optimal or satisfying decision, with a few exceptions (such as [24]); and (2) research on emotions in organizations mainly focuses on the employees, with exceptions such as $[3,8,25]$.

The research on emotions at workplace and in management is relatively scarce in developing countries, and mostly focuses on the employees' negative emotions (for example, [26-28]). Choosing Croatia for conducting the research on HR managers' emotions in a strategic decision-making event, contributes to the research on the topic in developing countries.

This chapter is followed by literature review that outlines the theoretical basis for the research. The methodology section explains the questionnaire formulation, distribution and sample selection. The results section presents the findings. The last section brings a discussion about the findings, possible implications, and future research directions, as well as study limitations. 


\section{Theoretical Basis}

\subsection{Strategic Decision-Making: Problem-Solving and Planning}

Strategic decision-making in the company involves fundamental decisions that shape the course: the decisions to enter a new market, to release a new product, or to acquire another firm. Eisenhardt and Zbaracki [29] broadly define strategic decision as "important, in terms of the actions taken, the resources committed, or the precedents set." More specifically, strategic decisions are about the long-term direction and the scope of the organization, gaining advantage over competitors, addressing changes, organizational capability and values, and expectation of the stakeholders [30]. Given its importance to the company, strategic decisions have been perceived as too relevant to allow for human error. The decisionmaker at the strategic level should first be aware of the gap between the real and the desired, then motivated to act, but also be talented to conduct clear analyses as well as to take bold actions. Therefore, extensive research has been devoted to rational and quantitative approach to strategic decision-making (modelling rational decision-making process, calculate optimal decision under constraints, measures of decision and outcome effectiveness, multi-criteria decision-making — for example [31,32]). For a long time, strategic decision-making has also been a part of the ongoing antagonism present in the decision-making research between emotions and decision-making, along with other dichotomies on the subject-irrational vs. logical, intuitive vs. deliberate thinking, hot affect vs. logic [23]. However, human factor and related characteristics could not have remained ignored permanently. Following the rational and analytical focus, the research on strategic decision-making shifted toward cognitive and behavioral approach (see [4] for extensive review). According to [4], "individual emotions are essential driving forces in strategic decision-making."

Strategic decision-making mostly occurs in two major event types: strategic planning and strategic problem-solving. Strategic decision-making involves problem formulation or goal identification, developing and generation of alternatives, and selection and evaluation $[4,33]$. According to Lynch [34] key elements of strategic decisions are: existing and new customers, implementation processes to deliver the strategy, offering sustainable competitive advantage, exploiting linkages between the organization and its environment, and developing the vison and purpose. From this perspective, the main difference between strategic planning and strategic problem-solving is whether the first stage involves formulation of a problem or identification of a goal. However, the differences arise from other perspectives. While strategic planning refers to continuous and repetitive (expected) process, solving a strategic problem may be caused by abrupt (unexpected) changes in the environment that require prompt reaction (proactive or reactive). In fact, a large portion of strategic problem-solving involves predicting strategic problems that the organization is expected to encounter.

By strategic planning we mean the formalization of the strategic process in organizations. Companies have two very important processes of strategic planning: one strategic planning process that defines business direction and strategy for the long-term and the other one which is focused on strategic assets and products but impacting mid-term horizon [35]. Decades ago, the authors warned that strategic planning is not an isolated event but a continuous activity that responds to event pressures and calendar requirements. This activity consists of long-term, medium-term, and short-term planning [36] which have to be integrated and implemented. With more intensive development of strategic management, the authors, led by [37], conclude that strategic planning is a formalized process that is not a substitute for careful and innovative thinking about major strategic outcomes and that the role of strategic planning is to summarize major strategic decisions taken elsewhere (perhaps in a management meeting) and that is useful for strategy operationalization $[30,38]$. Nonetheless, a strategic planning system may play a role in how the future organizational strategy is determined, as well as in the strategic analysis of an integrated planning system and in the process of decision-making. 
Strategic problem-solving refers to the process of identifying a strategic problem and generating ideas and an action plan to address this problem. Problem-solving often involves giving a quick response to a defined situation. It implies good horizontal and vertical coordination of the organization, especially when the problem-solving activities point to how digital technologies and the internet provide added value to firms' operations by identifying problems or needs and generating ideas and action plans to address those needs [39]. Problem-solving is the process of identifying the difference between the current state of the system and the desired state and acting to eliminate the observed differences. The problem-solving process is complex and consists of a series of related successive activities that implicitly or explicitly include the following steps: identifying and defining the problem, generating options or alternatives, evaluating options, selecting an option, implementing and evaluating results to determine whether problem-solving is satisfactory [40]. According to [41], every intended strategy will outgrow itself and transform into the realized one which will further require new problem-solving and adjustment of strategic plans. Strategic decision-making and strategic planning are an integral part of the company's strategies, which are "the pattern or plan that integrates an organization's major goals or policies and action sequences into a cohesive whole. It usually deals with the general principles for achieving the objectives: why the organization has chosen this particular route." [38]. In strategy development strategic decision-making occurred in three areas: (1) Context by which it is implied the environment within which the strategy operates and is developed; (2) content in which the main actions of the proposed strategy are specified; (3) process-connectivity and interaction of major activities in a changing environment [38]

Decision-making in this perspective, no matter whether the organization is large or small, for-profit or non-, takes time, and on the other hand, a considerable period is need-ed to see the effects of the decisions made. Simultaneously, decisionmakers know that each stakeholder can voice their own business judgment on the chosen strategy which may alter the original and every subsequent decision. Given this aspect of their differences, it is safer to assume that events of strategic planning and problem-solving will involve different emotions and different intensities of these emotions.

\subsection{Emotions in (Strategic) Decision-Making}

Most theorists agree that emotion is a reaction to a stimulus and has a range of possible consequences [42]. According to [43], there are three steps in the emotional registration process: attention, schemata, and feeling rules. The first step, attention, does not necessarily have to be a conscious attention, but also preconscious. Attention can also include intentional attention to events that are not common and worth noticing, compared to those that are negligible. The second step, schemata, indicates that the emotional registration process is deeply contextualized. There is great variability in the emotional responses that an event can produce. The third step, emotional rules include the sense of feeling (including intensity and duration) and can be described verbally like any other rule. The rules of feeling also include a normative focus toward pleasure rather than pain avoidance and psychodynamic concepts such as defense mechanisms and drivers. Emotional needs lead us to shape our real environment and interpretation of it in order to lead us to our desired emotional states. Authors $[44,45]$ conclude that emotions emerge from the act of engaging in work itself.

There are two main approaches to defining emotions that differ by consideration of the biological (evolutionary) aspect of emotions. The social constructionist approach considers social aspect of emotions, allowing for the variability in emotions, but does not consider the biological basis of emotions [46]. An approach that takes the biological aspect into account involves distinctive states of each emotion and its biological contribution and is usually referred to as the basic emotions approach or discrete emotions approach. The initial list of basic emotions involved six emotions, but few researches suggested an extended list of eight basic emotions, and [47] proposes that each emotion from his extended list of basic emotions satisfies the requirements for being a distinct psychological phenomenon. 
Psychological constructivists refer to basic emotions as elemental building blocks of emotion, which "are mental events that result from the interplay of more basic psychological ingredients that are themselves the result of evolution" [46]. Psychological constructivist approach does not separate the emotions by a pleasant and unpleasant state. Appraisal theories (which also consider biological base of emotions) account for emotional variability and allow existence of any emotion that is a meaning combination [46]. Appraisal theories also consider valence of emotions, which is dimensional conceptualization of intrinsic attractiveness of emotions, but can occur at different levels [48]. The valence approach differentiates positive and negative emotions due to their hedonistic tone or valence. Pfister, and Böhm [23] heavily criticize the valence approach: mapping emotions on one scale of valence resembles a utility scale and fails to capture possibility of emotional inclusivity, as well as the specific mechanisms which specific emotion triggers. Basic emotions are in focus of the feeling-as-information theory [49], which also offers a critique to the valence approach: emotions of the same valence may lead to different cognitive and behavioral outcomes, and the similar cognitive and behavioral outcomes may occur for the emotions of different valences. However, the limitation of the strict discrete approach refers to the use of only six basic emotions, which can reveal only a part of the experienced emotions in the work environment and neglects the impact which other emotions may have on the outcomes [50]. In addition, while using the valence framework, the research which examines the relationship between emotions and outcomes usually examines each emotion in relation to the outcome and not necessarily a group of emotions of the same valence (for example, [51]). Such methodological approach also enables the comparison of findings between different streams of thought (keeping in mind other differences in research design and measurement). Probably because of its simplicity and easy application, the valence approach to emotions is one of the most frequently used approaches in organizational behavior research (along with the basic emotions approach). Robins and Judge [52] suggest 18 emotions related to events at work: happiness, sadness, fear, anger, disgust, surprise, contempt, enthusiasm, envy, frustration, disappointment, shame, hope, jealousy, joy, love, pride. In comparison, [53] found 16 emotions to be job-related: pride, elation, joy, satisfaction, relief, hope, interest, surprise, sadness, fear, shame, guilt, envy, disgust, contempt, and anger (for different approaches see [54,55] systematization), where the first eight are emotions of positive valence and the rest are emotions of negative valence. In comparison to discrete emotions approach, the valence approach offers a wider variety of emotions which can relate to complex experience of events in work environment and as such, offers a more detailed insight. The appeal of the valence approach also lies in the possibility of comparing results to previous research on the subject and the dimension of arousal. Besides the existence of emotions, the valence approach also considers the arousal or the emotion intensity. Given that research [2,3,17] revealed possible coexistence of emotions of both positive and negative valence during an event, when determining the emotional aspects of distinct events-beside the emotion occurrence-the distinction may arise from the emotion intensity. We adopt the valence approach for this research, but keeping in mind the critique of this approach, we will refer to emotions as dominantly positive or negative valence-wise (allowing different perceived experience of emotions) and examine occurrence and intensities of each emotion in relation to the event.

The relationship between the emotions and cognition is described within two most frequently used frameworks in the organization behavior research: affective events theory [56] and cognitive appraisal theory [57]. Affective events theory suggests that positive and negative work events may be distinguishable as triggers of emotions and consequential behavior (such as job satisfaction or performance). According to the second theory, emotions follow the cognitive appraisal of the event and different cognitive appraisals of the same event may lead to very different emotional reactions $[4,58]$. While the event is the trigger in both approaches, in the first one, emotions precede cognition and in the second one, the relationship is transposed. However, [17] argues that the same event may be appraised from different perspectives and that appraisal may be the source of the revealed 
variety of emotions. We build on the affective events theory and [17] and propose that a uniquely experienced event with all its variety of emotions can be cognitively appraised from different perspectives: personal and organizational perspective.

\subsection{Previous Findings and Research Gaps}

Previous relatable findings mostly refer to the management of change, and an overview [4] identifies lack of control, involvement, and time perception as antecedents of emotions in strategic decision-making at individual level. The first one relates to uncertainty and unpredictability. The author also refers to previous findings [51] arguing that involvement in planning is related to enthusiasm and involvement in problem-solving is related to happiness. Time pressure results in negative emotions. However, [59] found that the time constraint level in combination with different emotions lead to different outcomes. In the first stage of strategic decision-making (problem formulation or goal identification), positive and negative emotions played a role in the efforts to achieve competing and focal goal, respectively $[4,60]$. According to the same author, in the second stage, "decisionmakers with negative emotions tend to categorize events or stimuli in more effortful and systematic ways because negative emotions indicate a threat to goal achievement" [4], while decisionmakers with positive emotions tend to be more flexible. This flexibility may relate to the feeling of certainty related to positive emotions and that perceived certainty can be assessed as adequate for judgement [4,61]. Ref [25] link uncertainty in work environment to fear as a discrete emotion. As the third stage of the process involves risk taking, fear and anxiety play a role in decision-making [62], and related research showed that negative emotions lead to less risk-taking, and the positive ones result in risk-seeking behavior [4].

Thus, for further empirical examination of the strategic decision-making events of strategic planning and problem-solving in this paper, we propose the following set of presumptions:

- Both events may be perceived as positive, neutral or negative (given the assumptions of the affective events theory);

- Both events will reveal the variety of involved emotions [2,3,17];

- The two events of strategic decision-making will trigger emotions in different intensities: given the event characteristics from the aspects of uncertainty and time pressure, the event of strategic planning will involve more dominantly positive emotions and the event of solving a strategic problem will involve more dominantly negative emotions (building on $[4,61]$ ); and the event of strategic problem-solving triggers emotions with higher level of intensity than the event of strategic planning;

- Both events can be assessed or cognitively appraised from different perspectives: personal and organizational (building on [17] arguments);

- The distinction between personal and organizational event appraisal will reveal differences in experienced emotions, as triggers of emotions may be personal or organizational aspects of events [3,17];

- Distinct strategic decision-making events will be related to job satisfaction;

- Emotions revealed during the strategic decision-making events will be related to job satisfaction.

\section{Methodology}

\subsection{Research Design and Hypotheses}

The existence and intensities of emotions in strategic decision-making has not been previously explored by quantitative approach and the goal of this research is to contribute to closing in that research gap.

Strategic decision-making occurs in two types: solving a strategic problem and strategic planning $[4,29,34]$. While the outcomes of both events determine the future of the company and its sustainability on the market, they differ because of the time pressure, uncertainty, risk, and control perception. Also, the involvement in strategic problemsolving and planning relates to different emotions [51], so it is appropriate to examine each event separately. 
This research does not examine the dynamics of emotions during the process, but after the event occurred. While this approach can be criticized because of the errors which may occur due to recalling emotions [53,63,64], Ref [3] showed that even two years after the major event for the company (mergers and acquisitions), the managers and key persons continue to express emotions related to the event. Besides, from the research point of view, strategic events are easier to identify after they occurred and managers are more willing to share their experiences after the event (sometimes, the confidentiality agreements prevent them from discussing events of strategic importance, especially before public announcement). As strategic decision-making events do not frequently occur in every firm, we will include the last two years as the relevant period for our research.

Strategic decision-making events are treated as affective events, the objects of emotions [65]. With that, we build on affective event theory, with the argument that the work events are triggers for emotions and consequently influence job satisfaction and performance. The same framework has been widely used in organizational research regarding emotions at work $[1-3,5,6,9,13,15,16,51,53]$. Building on the previous findings, it is expected that both events may be perceived as positive, neutral, or negative (given the assumptions of the affective events theory). Moreover, it is suggested that an event can be appraised differently from the personal perspective and organizational perspective [17]. We adopt that assumption and extend it to strategic decision-making events and expect that both events can be assessed or cognitively appraised from different perspectives: personal and organizational.

A part of the theorists [50] believe that there is no point in thinking only about fundamental feelings (anger, fear, sadness, happiness, disgust, surprise) because even rarely experienced feelings, such as pride or enthusiasm, can strongly affect persons' job satisfaction and job performance. We adopt that approach, and will examine the occurrence and levels of intensity for each of 18 emotions [52]: happiness, sadness, fear, anger, disgust, surprise, contempt, enthusiasm, envy, frustration, disappointment, shame, hope, jealousy, joy, love, pride, hate) related to the event. Given the set timeframe, the emotions present after the two-year period may differ from all the emotions experienced during the event, as managers' emotions may change with regard to their existence, dynamics, and intensity (as [3] showed in their study, different emotions prevailed in different time lapses after the event). However, when measuring the emotions related to an event as a whole (in this case, the event may refer to a prolonged period of time) and not a process, recalling summarized emotions is a reasonable approach. We expect that the event of strategic planning will involve more dominantly positive emotions and the event of solving a strategic problem will involve more dominantly negative emotions (building on $[4,66]$ ), as well as that the event of problem-solving triggers emotions with higher level of intensity than the event of strategic planning. Also, we expect that the relationships between emotions in an event will be present, implying their coexistence. In addition, we expect that the distinction between personal and organizational event appraisal will reveal differences in experienced emotions, as triggers of emotions may be personal or organizational aspects of events $[3,17]$.

Within the affective event theory, it is assumed that work events (hassles and uplifts) set off emotions that consequentially affect job satisfaction and performance [51,56,66-68]. We extend this presumption and examine whether there exists a relationship between emotions experienced during events of strategic decision-making to job satisfaction. We adopt previously explored approach $[67,68]$ that examines cognitive and affective aspect of job satisfaction.

To achieve the research goal, we impose following set of research objectives within the theoretical framework, in line with previously stated theoretical presumptions: 1 . To examine if a strategic decision-making event can be distinctly perceived as positive, neutral, or negative from the personal and organizational perspective; 2 . to examine which emotions occur in the two separate events of strategic decision-making, i.e., problem-solving and planning; 3. to compare occurrences and intensities of emotions that occur in the two events given their dominant valence; 4 . to examine the patterns of coexistence of 
emotions' intensities; 5 . to examine the relationship between event appraisal and emotions to job satisfaction.

To achieve the research goals and objectives, we introduce the following set of theoretical and testable hypotheses in line with previously stated propositions:

- $H_{1}$ : The events of strategic decision-making from the personal and organizational perspective can be distinctly appraised from the personal and organizational perspective.

- $\quad H_{1 a}$ : There is no statistically significant difference in the appraisals of events of strategic problem-solving from the personal and organizational perspective.

- $H_{1 b}$ : There is no statistically significant difference in the appraisals of events of strategic planning from the personal and organizational perspective.

- $\mathrm{H}_{2}$ : The events of strategic decision-making are triggers of variety of emotions: both dominantly positive and negative emotions.

- $H_{2 a}$ : The events of strategic problem-solving are triggers of both dominantly positive and negative emotions.

- $H_{2 b}$ : The events of strategic planning are triggers of both dominantly positive and negative emotions.

- $H_{3}$ : There are differences in intensities of experienced emotions given the event appraisal from personal and organizational perspective.

- $H_{3 a}$ : There are no differences in intensities of experienced emotions given the event of strategic problem-solving appraisal from personal and organizational perspective.

- $H_{3 b}$ : There are no differences in intensities of experienced emotions given the event of strategic planning appraisal from personal and organizational perspective.

- $H_{4}$ : Dominantly positive emotions positively correlate and dominantly negative emotions negatively correlate to event appraisal.

- $\quad H_{4 a}$ : There are no statistically significant positive and negative correlations of dominantly positive emotions and dominantly negative emotions, respectively, to event of strategic problem-solving appraisal.

- $H_{4 b}$ : There are no statistically significant positive and negative correlations of dominantly positive emotions and dominantly negative emotions, respectively, to event of strategic planning appraisal.

- $H_{5}$ : There exist positive correlations between emotions of dominantly positive and negative valence which are an indication emotions coexistence.

○ $\quad H_{5 a}$ : There are no statistically significant correlations between emotions of dominantly positive and negative valence in the event of strategic problem-solving.

(a) $\quad H_{5 b}$ : There are no statistically significant correlations between emotions of dominantly positive and negative valence in the event of strategic planning.

- $H_{6}$ : There are no differences in intensities of experienced emotions given the events of strategic problem-solving and planning.

- $H_{7}$ : There exists correlation between the event appraisal and job satisfaction.

- $H_{7 a}$ : There are no statistically significant correlations of strategic problemsolving event appraisal from personal and organizational perspective to cognitive aspect of job satisfaction.

- $H_{7 b}$ : There are no statistically significant correlations of strategic problemsolving event appraisal from personal and organizational perspective to affective aspect of job satisfaction.

- $\quad H_{7 c}$ : There are no statistically significant correlations of strategic planning event appraisal from personal and organizational perspective to cognitive aspect of job satisfaction.

- $\quad H_{7 d}$ : There are no statistically significant correlations of strategic planning event appraisal from personal and organizational perspective to affective aspect of job satisfaction. 
- $H_{8}$ : There exist correlations between the intensities of emotions and job satisfaction.

- $H_{8 a}$ : There are no statistically significant correlations of emotions' intensities to cognitive and affective aspect of job satisfaction, when controlled for the strategic problem-solving event appraisal.

- $\quad H_{8 b}$ : There are no statistically significant correlations of emotions' intensities to cognitive and affective aspect of job satisfaction, when controlled for the strategic planning event appraisal.

The conceptual framework and hypotheses are presented in Figure 1.

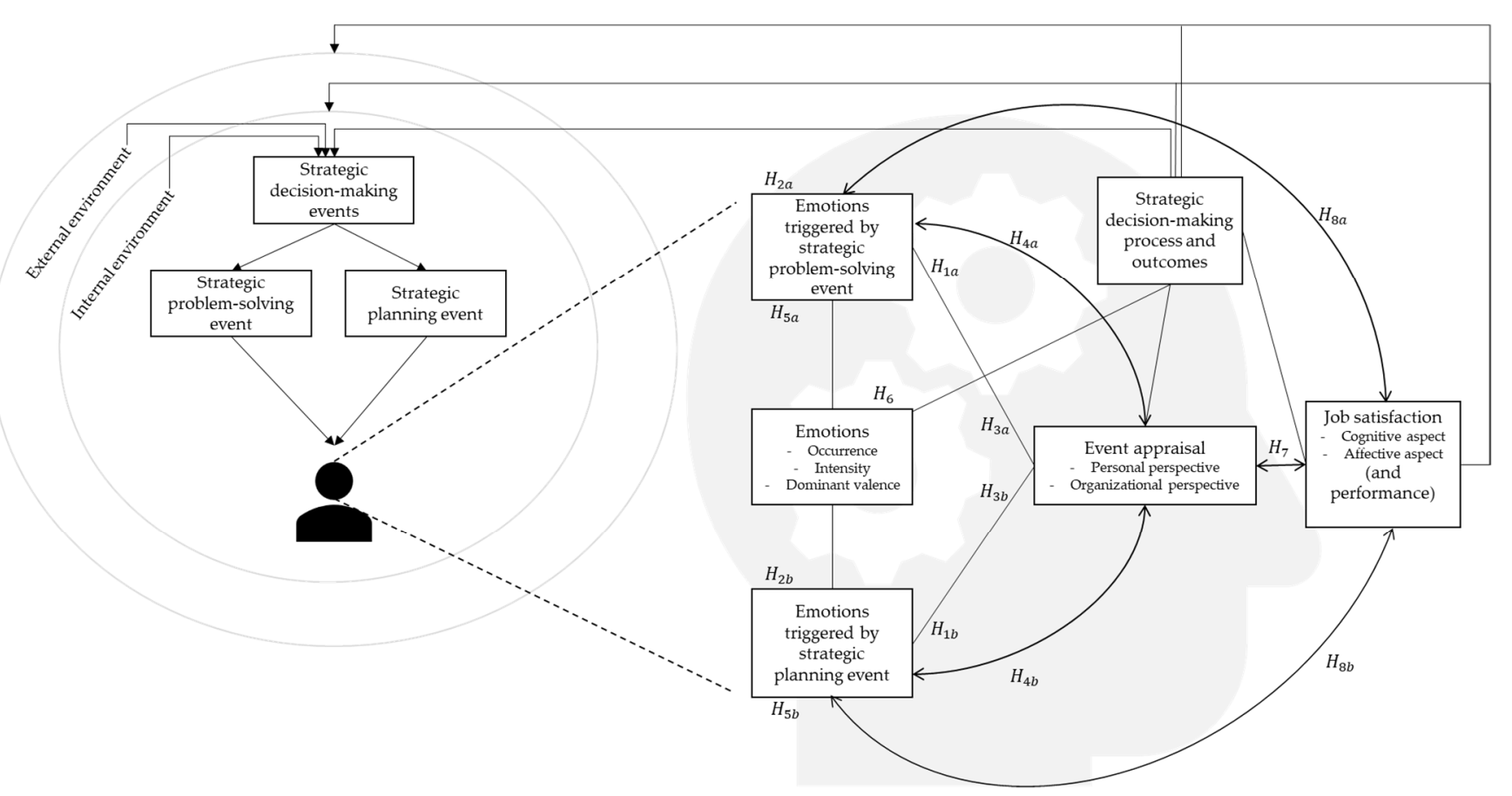

Figure 1. Conceptual framework and hypotheses.

When examining emotions in social sciences, interviews [2,3] and surveys [51,53] are most common means for obtaining data. While interviews enable in-depth analysis, surveys are frequently adopted as they enable researchers to reach wider number of respondents, they are less time consuming for both researcher and the respondent (as HR managers tend to have busy schedules) and are more appropriate in the case of quantitative analysis. According to [68], most social studies tend to use self-reported data, and that approach is adopted for this study. To conduct a survey in line with the set hypotheses, a questionnaire was assembled.

\subsection{A Questionnaire}

A questionnaire was formed to examine the occurrence and intensities of emotions in strategic decisions in line with the research goal, objectives, and set hypotheses. The questionnaire is based on the previous research and combines adapted approaches previously used in the research on the emotions in the workplace.

The first question required recalling and describing an event of solving a strategic problem. The description of the event is used to recall and conceptualize the related emotions, as [69] argues, "people experience an emotion when they conceptualize an instance of affective feeling."

The second and third questions require the appraisal of the event as positive, negative, or neutral from the personal perspective and from the perspective of the organization (e.g., for you, the event was: positive, neutral or negative; for the organization, the event was: positive, neutral or negative). Such approach allows different cognitive appraisal of 
the event [17]. While there is an ongoing academic discussion about the classification of emotions as positive or negative, the appraisal of events as positive, neutral, or negative may be provided from the experience or consequences point of view.

Following the appraisal, the respondents are required to denote the levels of intensity for each of the 18 emotions [52]: happiness, sadness, fear, anger, disgust, surprise, contempt, enthusiasm, envy, frustration, disappointment, shame, hope, jealousy, joy, love, pride, hate) related to the event.

There are different instruments for measuring emotions in the self-reported approach and they can roughly be divided into: graphical, verbal, and numerical instruments, each with their benefits and shortcomings [53,70,71]. One of the main selection criteria is what must be measured about the emotion (occurrence, the amount of the emotion, behavioral expression of the emotion), and metric requirements for the statistical analysis in line with the research goal. While numerical expression has the most advantages regarding the analysis, previous research shows that people prefer verbal expressions and graphical instruments (varying from slider bars to smiley faces) to numerical ones, when asked about the emotions. The goal of this research shifts the measurement requirement to measurement of the intensity of emotions related to an event. To compromise between the approaches, we used combined measurement with verbal expressions only as markers at the beginning and the end (denoting complete absence of an emotion or maximum intensity of an emotion) and the slider bar as a form of graphical scale. The slider bar enables a more precise expression of the amount of the occurred emotion than a 5- or 7-item verbal scale. In addition, the slider bar enables ratio level of measurement in the interval from zero to 100 (and it can also be expressed in percentages), where zero denotes the absence of observed phenomenon.

Following the first set of questions, the other event was examined in the second section of the questionnaire: strategic planning its appraisal and the accompanying emotions. The goal of the separation and description of two business situations is to press managers to distinguish the business situation of strategic planning from strategic problem-solving, aware that sometimes there can be a very thin line between the two.

The third section of the questionnaire examines respondents' job satisfaction. The respondents were to choose the statement which best describes their level of job satisfaction in terms of the job-related events and the general feeling that the job inspires from the cognitive and affective perspective, which is a variation of the [66-68] job satisfaction examination, inspired by research of frequency of affective events.

The last section examines the following socio-demographic characteristics: age, gender, education level, area of expertise (in which the highest degree was achieved), total length of service, length of service at managing positions, and participation in education about recognizing and managing emotions. As the work environment aspects may inspire different emotions and their expression [50], the type and size of the organization where the examined managers work (profit, non-profit, state, public; micro, small, medium, large according to classification by Accounting Act NN 120/16, 116/18 [72]) were examined.

Prior to its distribution, the questionnaire was approved by the Research Ethics Assessment Committee with the authors' home institution. The questionnaire can be found in Appendix A.

\subsection{Data Collection}

What all organizations should have in common is: analysis of the environment or strategic analysis, vision and mission, strategic goals and medium-term and short-term plans (the time horizon may differ). We also assume that despite the differences that sample units may have in the principles of strategic management, and especially in the process of strategic management, the core plans are developed in each and these plans require the same strategic logic, reflection, argumentation, and decision-making. Similarly, we assume that regardless of the organization size, strategic problem-solving is the process of identifying a strategic problem and generating ideas and an action plan to address this 
problem. We considered that our sample of HR managers includes companies of different sizes, i.e., that small companies will have a simpler and shorter planning system and will be able to respond more quickly to changes in the environment.

To meet the criteria for involvement, the respondents had to hold a HR function at the time a questionnaire was filled in. The second criterion was that the respondents were a part of the strategic decision-making processes of solving a strategic problem and strategic planning within the last two years.

The questionnaire was distributed online in January and February of 2020 (prior to lockdown in Croatia, in March 2020), with the help of the Human Resources Development Community at the Croatian Chamber of Commerce, to registered HR managers in Croatia. The participation in the survey was voluntary, hence a convenience sample is obtained. There were 119 respondents who approached to filling in the survey, but after the exclusion of the incomplete and unusual cases, as well as the responses which did not meet the criteria, 55 responses remained for the analysis of solving a strategic problem, 48 for the analysis of strategic planning, while only 45 respondents provided the responses to the last section of the questionnaire. Given that there were 250 registered HR managers in the Human Resources Development Community at the time survey was conducted, the marginal error for the given sample suggests that there is $95 \%$ chance that the real values are between $\pm 4.12 \%, 4.36 \%$, and $4.55 \%$ of measured values for the first, second, and third part of the survey, respectively. However, any generalization of the results may refer only to the registered HR managers.

\subsection{Sample Characteristics}

Reported data are based on the 55 responses for the first section of the survey, 48 for the second section, while only 45 respondents provided the socio-demographic data and data on organization size and type, as well as satisfaction evaluation. The survey is biased gender-wise, as there are 30 female and 15 male respondents. The respondents' age varies from 25 to 66, with an average age of 45.69 and standard deviation of 11.38 years. Their years of service vary from 1 to 40 , with an average of 20.29 years and standard deviation of 11.06 years. Their experience in the managing positions varied from 1 to 25 years, with an average of 10.67 years and standard deviation of 6.94 years. In terms of education, there are 4 managers with high school education, 4 undergraduate level, 27 graduate level, 5 master's level, 2 doctoral level and 3 with other kind of education. In terms of the field of science, 6 respondents obtained their degree in technical sciences, 30 in social sciences, 8 in humanities and 1 in interdisciplinary field of science. In terms of the company type, 32 respondents work in profit organizations, 6 of them in government institutions, regional and local government and self-government units or an agency, and 7 of them in public interest entities. The organizations that are subject to corporate accounting are additionally scrutinized in terms of the size and number of employees. There are HR managers from 11 micro, 9 small, 8 medium, and 7 large companies. Among them, 14 respondents work in companies that employ 10 persons or less, 12 in companies that employ 11-50 employees, 13 in companies that employ 51-250 employees, and 6 in companies that employ more than 251 employees.

\subsection{Data Analysis}

To gain initial insights, the data are presented using descriptive statistics. The descriptive statistics enable insights into the frequency of occurrence of each emotion, the average intensities of each emotion, as well as distribution dispersion, skewness, and kurtosis. Such data presentation enables determination of emotion occurrence, or more precisely whether more emotions exist during an event $\left(\mathrm{H}_{2}\right)$. While descriptive statistics provides insight into data, non-parametric tests reveal differences in the subsets of the data.

Initial observations of the data and applied tests showed that the data are not normally distributed. In addition, the event appraisal and the job satisfaction are measured as ordinal variables, where parametric methods should not be applied. Because of these limitations, 
non-parametric hypothesis testing $\left(H_{1}, H_{3}, H_{6}\right)$ and non-parametric correlation analysis $\left(H_{4}, H_{5}, H_{7}, H_{8}\right)$ are conducted to test the hypotheses.

\section{Results}

The results section is divided into results related to strategic problem-solving, strategic planning, and job satisfaction.

\subsection{Solving a Strategic Problem}

While there are differences in the event appraisal ( $n=3$ for negative, $n=1$ for neutral and $\mathrm{n}=4$ for positive; there were 10 differences in appraisals of events when observing individual cases), it can be noticed that the majority of respondents $(82.14 \%)$ appraised the events the same way from both perspectives (Table 1). This seems to confirm that an event can be appraised from different perspectives and indicates that some HR managers may perceive the same event differently from the perspective of the organization and from a personal perspective, which is in line with [17]. However, the observed differences are not large enough to appear as statistically significant (Wilcoxon signed ranks test shows that with $p>0.05$ the null hypothesis cannot be rejected), thus we must conclude that for the event of strategic problem-solving $H_{1 a}$ cannot be rejected. That is not in line with presumption about the differences in event appraisal from the personal and organizational perspective-at least not for the strategic problem-solving event at $5 \%$ statistical significance level. Nevertheless, we are not ready to fully abandon that presumption. First, the data show that roughly one-fifth of the respondents does make the distinction. While this is not enough for achieving statistical significance, it still shows that respondents can differently appraise the events from personal and organizational perspective. Second, while the respondents can appraise the event from different perspectives it does not mean that they have to appraise it differently, as contextual characteristics of the event may support the same appraisal of the event from personal and organizational perspective.

The descriptive statistics points to average moderate experience of emotions' intensity related to the event of solving a strategic problem, with the exception of envy, shame, jealousy and hate that are very low on average. The variation of expressed emotions is rather high for most of the expressed emotions, which shows variability between individuals.

The respondents experienced from 3 to 17 emotions related to the event, with an average occurrence of 9 emotions. The emotion with the highest number of occurrences is hope, followed by pride, enthusiasm, and happiness (Table 1). The lowest number of occurrences refers to hate, envy, and jealousy. While emotions vary given their occurrence and intensity, it can be noticed that most respondents experienced a variety of emotions related to an event of strategic problem-solving, which confirms $\mathrm{H}_{2 a}$.

Given the variability, it makes sense to look deeper into the data and examine the descriptives regarding the appraisal of the events. The respondents classified the events from the personal perspective and from the perspective of the organization.

Given the variability, it makes sense to look deeper into the data and examine the descriptives regarding the appraisal of the events, in line with the research objective to determine which emotions occur and in what intensity during the event. The respondents classified the events from the personal perspective and from the perspective of the organization.

When observing the emotion intensity after data separation by event appraisal, it can be noticed that, on average, frustration and disappointment are the most prominent emotions and occur with high average intensity for negative events (Table 1). This finding is not in line with the previous research that linked happiness to problem-solving [51]. For respondents who appraised the event as positive, the emotion with the highest average intensity is enthusiasm, followed by pride, hope, joy, and happiness. In case of a neutrally appraised event, frustration and hope appear with higher intensity for both appraisal perspectives. In case of negatively appraised events, frustration is the most pronounced, followed by disappointment, sadness, and anger. 
Table 1. Descriptive statistics of intensities of experienced emotions during the strategic problem-solving event.

\begin{tabular}{|c|c|c|c|c|c|c|c|c|c|c|c|c|c|c|c|c|c|c|c|}
\hline \multirow{3}{*}{ Emotions } & \multirow{2}{*}{\multicolumn{7}{|c|}{$\begin{array}{l}\text { Experienced Emotions Related to the Event of } \\
\text { Solving a Strategic Problem }\end{array}$}} & \multicolumn{6}{|c|}{ Event Appraisal from a Personal Perspective } & \multicolumn{6}{|c|}{$\begin{array}{l}\text { Event Appraisal from the Perspective of } \\
\text { the Organization }\end{array}$} \\
\hline & & & & & & & & \multicolumn{2}{|c|}{ Negative, $\mathrm{n}=11$} & \multicolumn{2}{|c|}{ Neutral, $n=6$} & \multicolumn{2}{|c|}{ Positive, $n=42$} & \multicolumn{2}{|c|}{ Negative, $\mathrm{n}=11$} & \multicolumn{2}{|c|}{ Neutral, $n=6$} & \multicolumn{2}{|c|}{ Positive, $\mathrm{n}=40$} \\
\hline & Min & Max & $\mathbf{o}$ & $\mu$ & s & Sk & K & $\mu$ & s & $\mu$ & $\mathbf{s}$ & $\mu$ & s & $\mu$ & $\mathrm{s}$ & $\mu$ & s & $\mu$ & $\mathbf{s}$ \\
\hline anger & 0 & 100 & 24 & 25.24 & 35.100 & 1.002 & -0.592 & 64.36 & 36.65 & 32.00 & 41.74 & 12.84 & 24.069 & 59.50 & 40.27 & 24.40 & 28.58 & 18.81 & 31.538 \\
\hline contempt & 0 & 100 & 15 & 12.40 & 26.833 & 2.371 & 4.363 & 38.36 & 42.53 & 26.50 & 37.69 & 2.66 & 6.317 & 40.75 & 46.24 & 0.20 & 0.45 & 8.45 & 19.807 \\
\hline enthusiasm & 0 & 100 & 47 & 62.44 & 36.444 & -0.680 & -1.047 & 38.55 & 42.40 & 46.50 & 31.74 & 71.87 & 31.845 & 33.63 & 40.27 & 46.20 & 29.58 & 69.86 & 33.714 \\
\hline envy & 0 & 50 & 8 & 3.80 & 10.130 & 3.135 & 9.837 & 4.09 & 8.87 & 9.50 & 15.67 & 2.82 & 9.435 & 5.50 & 10.20 & 0.20 & 0.45 & 3.90 & 10.734 \\
\hline fear & 0 & 99 & 36 & 28.93 & 30.001 & 0.812 & -0.464 & 54.27 & 40.46 & 30.67 & 27.81 & 21.32 & 22.709 & 42.75 & 40.21 & 25.20 & 28.07 & 26.74 & 28.084 \\
\hline frustration & 0 & 100 & 39 & 44.44 & 38.717 & 0.132 & -1.617 & 91.09 & 10.59 & 50.00 & 45.24 & 30.05 & 31.879 & 90.00 & 10.90 & 50.60 & 31.33 & 35.02 & 36.848 \\
\hline disappointment & 0 & 100 & 36 & 34.75 & 38.353 & 0.644 & -1.305 & 84.64 & 24.25 & 53.00 & 46.29 & 17.42 & 24.413 & 83.63 & 28.30 & 40.20 & 37.98 & 24.79 & 32.992 \\
\hline shame & 0 & 70 & 11 & 6.62 & 16.676 & 2.651 & 5.849 & 16.00 & 26.68 & 11.17 & 22.31 & 3.18 & 10.224 & 22.00 & & 10.00 & 21.81 & 3.29 & 9.920 \\
\hline disgust & 0 & 100 & 13 & 12.49 & 26.520 & 2.254 & 4.049 & 47.18 & 39.23 & 23.83 & 25.05 & 0.66 & 1.820 & 62.63 & 29.12 & 0.00 & 0.00 & 4.43 & 14.338 \\
\hline happiness & 0 & 100 & 43 & 49.35 & 37.935 & -0.089 & -1.500 & 16.18 & 32.69 & 40.17 & 38.58 & 60.39 & 33.828 & 13.25 & 33.58 & 41.80 & 25.97 & 57.12 & 36.248 \\
\hline hate & 0 & 90 & 6 & 3.62 & 14.172 & 5.181 & 28.479 & 6.73 & 16.04 & 17.83 & 36.00 & 0.47 & 1.606 & 7.25 & 18.50 & 0.00 & 0.00 & 3.36 & 14.207 \\
\hline hope & 0 & 100 & 51 & 66.93 & 31.569 & -0.841 & -0.257 & 66.55 & 37.55 & 56.00 & 42.16 & 68.76 & 28.467 & 59.88 & 41.14 & 63.00 & 31.51 & 68.74 & 30.196 \\
\hline jealousy & 0 & 53 & 8 & 3.58 & 10.542 & 3.684 & 13.795 & 1.55 & 4.50 & 9.33 & 12.36 & 3.26 & 11.375 & 2.13 & 5.25 & 0.00 & 0.00 & 4.29 & 11.798 \\
\hline & 0 & 100 & 41 & 50.84 & 40.436 & -0.113 & -1.675 & 18.82 & 30.23 & 44.00 & 48.61 & 61.18 & 37.386 & 21.00 & 32.30 & 30.80 & 41.27 & 58.90 & 38.985 \\
\hline love & 0 & 100 & 24 & 23.07 & 34.877 & 1.283 & 0.097 & 9.27 & 18.21 & 28.00 & 38.14 & 26.29 & 37.656 & 15.25 & 29.67 & 12.40 & 21.65 & 25.83 & 37.047 \\
\hline pride & 0 & 100 & 48 & 61.75 & 37.210 & -0.563 & -1.176 & 42.00 & 36.72 & 51.50 & 32.89 & 69.08 & 36.360 & 49.88 & 33.98 & 23.00 & 43.45 & 68.62 & 34.400 \\
\hline surprise & 0 & 100 & 33 & 32.29 & 33.096 & 0.581 & -1.013 & 46.82 & 40.22 & 26.50 & 40.23 & 29.00 & 29.385 & 53.88 & 37.22 & 23.80 & 23.61 & 29.19 & 32.282 \\
\hline sadness & 0 & 100 & 24 & 20.40 & 30.228 & 1.425 & 0.837 & 61.18 & 39.07 & 16.33 & 21.47 & 9.24 & 15.285 & 61.13 & 35.65 & 22.00 & 25.88 & 12.45 & 23.074 \\
\hline
\end{tabular}

Notes: o stands for a number.

sample kurtosis, $\mathrm{n}=56$. 
While the emotions of dominantly positive valence occur with regard to positive events and those of dominantly negative valence with regard to negative events, it is interesting to notice that hope is, on average, at least moderately expressed as experienced emotion regardless of the event appraisal, as well as the most frequently reported emotion (so it seems that the saying "there's always hope" is true for HR managers).

It can also be noticed that a neutrally appraised event reveals emotions with lower average intensities in comparison to negatively and positively appraised events, both from a personal and organizational perspective. Given the affective events theory, and this data, it can be assumed that the event valence is not just the trigger for the emotion occurrence, but also for the intensity of the related emotions.

To examine if there is a difference in intensity of experienced emotions given the event appraisal from different perspectives $\left(H_{3 a}\right)$, a non-parametric hypothesis testing was conducted and the results show statistically significant differences in the intensity of the most experienced emotions, if observed at $10 \%$ statistical significance. There is no statistically significant difference in the amount of envy, shame, hope, love, and surprise regarding the event appraisal from a personal perspective (Table 2). The same is true for the event appraisal from the organizational perspective.

Table 2. Non-parametric tests of differences in expressed emotions given the strategic problemsolving event appraisal.

\begin{tabular}{ccc}
\hline Emotions & $\begin{array}{c}\text { Event Appraisal from a } \\
\text { Personal Perspective }\end{array}$ & $\begin{array}{c}\text { Event Appraisal from the } \\
\text { Organizational Perspective }\end{array}$ \\
\hline Anger & $15.21^{* * *}$ & $7.037^{* *}$ \\
Contempt & $14.449^{* * *}$ & $9.012^{* *}$ \\
Enthusiasm & $6.71^{* *}$ & $6.885^{* *}$ \\
Envy & $0.291^{*}$ & 0.422 \\
Fear & $5.332^{* * *}$ & 0.694 \\
Frustration & $20.383^{* * *}$ & $12.668^{* * *}$ \\
Disappointment & $22.878^{* * *}$ & $13.823^{* * *}$ \\
Shame & $3.442^{* * *}$ & $1.981^{* *}$ \\
Disgust & $22.731^{* * *}$ & $25.213^{* * *}$ \\
Happiness & $11.531^{* * *}$ & $9.137^{* * *}$ \\
Hate & $8.304^{* *}$ & $7.181^{* *}$ \\
Hope & $0.577^{*}$ & $0.448^{*}$ \\
Jealousy & $4.367^{* * *}$ & $1.344^{* *}$ \\
Joy & $7.713^{* *}$ & $6.156^{* *}$ \\
Love & $1.257^{* *}$ & $0.851^{* *}$ \\
Pride & $6.911^{* *}$ & $3.066^{* *}$ \\
Surprise & $2.299^{* * *}$ & $11.768^{* * *}$ \\
Sadness & $15.012^{* * *}$ & .
\end{tabular}

Notes: reported values are Chi-square results of Kruskal Wallis tests; $\mathrm{df}=2 ; \mathrm{n}=55$; statistically significant differences at $10 \%, 5 \%$ and $1 \%$ level are denoted $* * *$ and ${ }^{* * *}$, respectively.

If we observe only statistical differences at $1 \%$ level (Table 2), the results reveal differences in anger, disgust, happiness, sadness, contempt, frustration, and disappointment regarding the event appraisal from a personal perspective; and disgust, sadness, contempt, frustration, and disappointment regarding the event appraisal from a personal perspective. This shows that mostly dominantly negative valence emotions vary depending on a particular event appraisal for the observed HR managers. The results point out to rejection of the $H_{3 a}$ for the statistically significant emotions, meaning that there are differences in intensities of experienced emotions given the event appraisal from personal and organizational perspective.

Moreover, the revealed differences (at 1\% level) do not match for the two event appraisals and reveal statistically significant differences in two emotions more for the event appraisal from a personal perspective (anger and contempt). The above confirms that HR managers can differentiate the event from a personal and organizational perspective and that for some of them, the evaluation of the event will be different from a personal and organizational perspective, and that emotions play a role in these distinctions-which 
supports the presumption related to the first hypothesis. In order to understand the source of variation, it is important to mention that all the differences in the respondents' event appraisal reveal more positive classification of the event from the perspective of organization, which also limits the interpretation. The intensity of experienced anger and contempt may be an indication of the difference in HR managers' appraisal of the event from the organizational and personal perspective, when the event is assessed as worse from the personal perspective than from organizational.

The provided analysis indicates that some emotions co-occur given the event, which requires additional analysis. Then, it is examined whether the occurrence of emotions correlates to the event appraisal.

The correlation between the event appraisal and emotions is assessed using the nonparametric Kendall Tau-b correlation coefficient, with applied stratified bootstrap based on event appraisal (to compensate for the small sample). Bootstrap results are based on 1000 stratified samples and reveal relatively small biases and standard errors and do not lead to an increase in data variability.

The analysis reveals weak to moderate statistically significant correlations (Table 3). There are positive correlations of enthusiasm, happiness, joy, and pride to event appraisal from a personal perspective; meaning that they occur in the higher intensity for positively assessed event and with lower intensity for the negatively assessed events, as expected. The negative correlations to event appraisal from a personal perspective are anger, contempt, fear, frustration, disappointment, shame, disgust, hate and sadness; meaning that they occur with higher intensity for negative events and with lower intensity for the positive ones. Results point out to rejection of $H_{4 a}$ for stated statistically significant emotions, which means that there are statistically significant correlations and that dominantly positive emotions positively correlate and dominantly negative emotions negatively correlate to event appraisal.

Table 3. Non-parametric correlations between the strategic problem-solving event appraisals and emotion intensities.

\begin{tabular}{ccc}
\hline Emotions. & $\begin{array}{c}\text { Event Appraisal from a } \\
\text { Personal Perspective }\end{array}$ & $\begin{array}{c}\text { Event Appraisal from the } \\
\text { Perspective of the Organization }\end{array}$ \\
\hline Anger & $-0.459^{* * *}$ & $-0.301^{* *}$ \\
Contempt & $-0.450^{* * *}$ & -0.176 \\
Enthusiasm & $0.291^{* * *}$ & $0.301^{* * *}$ \\
Envy & $-0.029^{* *}$ & 0.050 \\
Fear & $-0.258^{* * *}$ & -0.076 \\
Frustration & $-0.477^{* * *}$ & $-0.381^{* * *}$ \\
Disappointment & $-0.526^{* * *}$ & $-0.387^{* * *}$ \\
Shame & $-0.214^{*}$ & $-0.178^{* *}$ \\
Disgust & $-0.589^{* * *}$ & $-0.401^{* * *}$ \\
Happiness & $0.380^{* * *}$ & $0.333^{* * *}$ \\
Hate & $-0.354^{* * *}$ & -0.194 \\
Hope & 0.026 & 0.074 \\
Jealousy & $-0.108^{* * *}$ & 0.052 \\
Joy & $0.297^{* * *}$ & $0.278^{* *}$ \\
Love & 0.086 & 0.097 \\
Pride & $0.300^{* * *}$ & $0.246^{* *}$ \\
Surprise & $-0.121^{* * *}$ & -0.153 \\
Sadness & $-0.449^{* * *}$ & $-0.389^{* * *}$
\end{tabular}

Notes: Kendall Tau-b correlation coefficients are reported; $n=55$; statistically significant differences at $10 \%, 5 \%$ and $1 \%$ level are denoted $* * *$ and $* * *$, respectively.

It can be noticed that contempt, fear, shame, and hate do not occur as statistically significant correlations with the event appraisal from the perspective of the organization. These differences in the statistically significant correlations between event appraisal from a personal and organizational perspective show that some emotions of dominantly negative 
valence play a role in the personal experience of the event, regardless of its meaning for the organization. This additionally confirms the results from the hypothesis testing, meaning that some events may be positive or neutral from the perspective of the company, but the role of the HR manager position puts the respondents in a situation which they perceive worse from their own perspective, which causes experience of different intensity of contempt, fear, shame, and hate.

The intensities of emotions correlate to the event appraisal, meaning that if we want to additionally explore the coexistence of emotions, the correlation analysis must be conducted such that it uses the event appraisal as a control variable.

Thus, partial correlation examination should reveal the relationships between the intensities of experienced emotions for observed HR managers $\left(H_{5 a}\right)$.

As it might have been expected, there are statistically significant and moderate positive correlations between the emotions of dominantly positive valence (E1-E6), regardless of the event appraisal (Table 4). The more intensely one of those emotions is experienced, it is likely that others will also be intensely experienced. The exception is strong positive correlation between happiness and joy, meaning that if happiness is intensely experienced, joy will be intensely experienced as well. The observed correlations between the emotions of the dominantly negative valence do not so consistently occur as those of the dominantly positive valence, but show some statistically significant correlations, which are positive regarding the direction and weak to moderate regarding the intensity.

Revealed correlations show that there is a relationship between the intensities of emotions, separately for group E1-E7 and group E8-E18, with stated exceptions. This reveals the coexistence of different emotions, regardless of the event appraisal, and leads to the rejection of $H_{5 a}$.

The most interesting observation occurs for the emotions that positively correlate to emotions both dominantly positive and negative in valence. There are statistically significant weak to moderate positive correlations between the intensities of experienced hope and fear, joy and fear, love and envy, love and jealousy, surprise and fear, surprise and disappointment, surprise and shame, surprise and disgust, and surprise and jealousy. Four emotions with dominantly positive valence positively correlate to emotions of dominantly negative valence, allowing not just for their coexistence but also for a relation in their intensities, which confirms $\mathrm{H}_{5}$ and the presumption of emotions coexistence.

Additional indication of the simultaneous existence of emotions for HR managers when solving a strategic problem is the lack of the statistically significant negative correlations between the emotions in group E1-E7 and group E8-E18. If negative correlation occurred, that would mean that as intensity of emotions E1-E7 rises, the intensity of emotions E8-E18 would diminish. Along with revealed positive correlations between emotions of different dominant valence, this finding allows the coexistence of the emotions of different dominant valence without the existence of linear relationship between them. The exceptions are weak and negative statistically significant correlation between the intensity of experienced enthusiasm and hate, pride and shame, and hope and hate; meaning that, for example, for higher intensity of experienced hope there will be lower intensity of experienced hate (and vice versa).

Along with the revealed positive correlations, the lack of negative correlations between most of the emotions from the two groups means that the existence of emotions from one group does not mean the absence of the emotions from the second group and confirms the previous findings by $[2,3,17]$.

Positive correlations between emotions in group E1-E7 and the same kind of correlation between the emotions in group E8-E18, but without the negative correlations between all of (or most of) the emotions of different groups, reveal the coexistence of the various emotions and indicates emotional turmoil of the HR managers when solving a strategic problem. 
Table 4. Non-parametric partial correlations of intensity of emotions with strategic problem-solving event appraisals as control variables.

\begin{tabular}{|c|c|c|c|c|c|c|c|c|c|c|c|c|c|c|c|c|c|c|}
\hline & E1 & E2 & E3 & E4 & E5 & E6 & E7 & E8 & E9 & E10 & E11 & E12 & E13 & E14 & E15 & E16 & E17 & E18 \\
\hline E1 & & $0.626^{* * *}$ & $0.616^{* * *}$ & $0.541^{* * *}$ & $0.400^{* * *}$ & $0.498 * * *$ & & & & & & & & & & $-0.291 * *$ & & \\
\hline E2 & $0.626^{* * *}$ & & $0.650^{* * *}$ & $0.791^{* * *}$ & $0.344^{* *}$ & $0.559^{* * *}$ & $0.318^{* *}$ & & & & & & & & & & & \\
\hline E3 & $0.616^{* * *}$ & $0.650^{* * *}$ & & $0.559 * * *$ & $0.292 * *$ & $0.500 * * *$ & & & & & $0.365 * * *$ & & & & & $-0.308^{* *}$ & & \\
\hline $\mathrm{E} 4$ & $0.541^{* * *}$ & 0.791 *** & $0.559 * * *$ & & $0.447^{* * *}$ & $0.539 * * *$ & & & & & $0.266^{*}$ & & & & & & & \\
\hline E5 & $0.400^{* * *}$ & $0.344^{* *}$ & $0.292 * *$ & $0.447^{* * *}$ & & $0.228^{*}$ & & & & $0.349 * * *$ & & & & & & & $0.303^{* *}$ & \\
\hline E6 & $0.498^{* * *}$ & $0.559 * * *$ & $0.500^{* * *}$ & $0.539 * * *$ & $0.228 *$ & & & & & & & & & -0.230 * & & & & \\
\hline E7 & & $0.318^{* *}$ & & & & & & & & & $0.349^{* * *}$ & & $0.508^{* * *}$ & $0.387^{* * *}$ & $0.291 * *$ & & $0.253 *$ & \\
\hline E8 & & & & & & & & & $0.489 * * *$ & & $0.245^{*}$ & $0.361^{* * *}$ & $0.236^{*}$ & $0.388^{* * *}$ & & & & \\
\hline E9 & & & & & & & & $0.489 * * *$ & & $0.322 * *$ & & $0.390^{* * *}$ & $0.252 *$ & $0.254 *$ & $0.592^{* * *}$ & $0.418^{* * *}$ & & $0.398^{* * *}$ \\
\hline E10 & & & & & $0.349 * * *$ & & & & $0.332 * *$ & & $0.253 *$ & & & $0.326^{* *}$ & $0.464^{* * * *}$ & $0.305^{* *}$ & $0.457 * * *$ & 0.271 ** \\
\hline E11 & & & $0.365^{* * *}$ & $0.266^{*}$ & & & $0.349 * * *$ & $0.245^{*}$ & & $0.253 *$ & & $0.379 * * *$ & $0.454^{* * *}$ & $0.501^{* * *}$ & & & $0.323^{* *}$ & $0.322 * *$ \\
\hline E12 & & & & & & & & $0.361^{* * *}$ & $0.390 * * *$ & & $0.379 * * *$ & & $0.611 * * *$ & 0.306 ** & $0.250 *$ & & & 0.307 ** \\
\hline E13 & & & & & & & $0.508^{* * *}$ & $0.236 *$ & $0.252 *$ & & $0.454^{* * *}$ & $0.611^{* * *}$ & & $0.379^{* * *}$ & $0.352 * * *$ & & $0.251 *$ & $0.494^{* * *}$ \\
\hline E14 & & & & & & $-0.230 *$ & $0.387 * * *$ & $0.388 * * *$ & $0.254 *$ & $0.326^{* *}$ & $0.501^{* * *}$ & $0.306 * *$ & $0.379 * * *$ & & $0.456^{* * *}$ & & $0.536 * * *$ & $0.393^{* * *}$ \\
\hline E15 & & & & & & & 0.291 ** & & $0.592 * * *$ & $0.464^{* * * *}$ & & 0.250 * & $0.352 * * *$ & $0.456 * * *$ & & $0.508^{* * *}$ & $0.544 * * *$ & $0.474^{* * *}$ \\
\hline E16 & $-0.291 * *$ & & $-0.308 * *$ & & & & & & $0.418^{* * *}$ & $0.305^{* *}$ & & & & & $0.508^{* * *}$ & & $0.265^{* *}$ & \\
\hline E17 & & & & & $0.303^{* *}$ & & $0.253 * *$ & & & $0.457^{* * *}$ & $0.323 * *$ & & $0.251 *$ & $0.536^{* *}$ & $0.544^{* * *}$ & $0.265^{* *}$ & & \\
\hline E18 & & & & & & & & $0.273^{* *}$ & $0.398^{* * *}$ & $0.271^{* *}$ & $0.322 * *$ & $0.307^{* *}$ & $0.494^{* * *}$ & $0.393 * * *$ & $0.474^{* * *}$ & & & \\
\hline
\end{tabular}

Notes: reported values are partial correlation coefficients; E1—enthusiasm, E2—happiness, E3—hope, E4-joy, E5—love, E6-pride, E7—surprise, E8—anger, E9—contempt, E10—envy,

E11—fear, E12-frustration, E13-disappointment, E14—shame, E15-disgust, E16-hate, E17—jealousy, E18—sadness; statistical significance levels of 10\%, 5\% and 1\% are denoted *** and ${ }^{* * *}$, respectively. 


\subsection{Strategic Planning}

In the event of strategic planning appraisal from personal and organizational perspective fewer differences in appraisal of strategic planning event occur ( 2 for negative and 2 for positive event appraisal), with 5 differences when observing individual responses. Stated differences were not enough to appear as statistically significant (Wilcoxon signed ranks test shows that with $p>0.05$ the null hypothesis $\left(H_{1 b}\right)$ cannot be rejected). The fact that $10.42 \%$ of respondents show the ability to differently appraise the events, shows that the presumption of different cognitive appraisal of the events should not be ignored. However, the hypotheses testing also shows that the different cognitive appraisal of strategic decision-making events (both strategic planning and problem-solving) is not common occurrence-it is rare. In the most cases of different appraisal for both events, the events are appraised as worse from personal perspective, which may be an indication of mismatching or disagreement in personal experience (including opinions and attitudes) to the organizational.

The highest number of occurrences refers to enthusiasm, hope, and happiness. Individually (per respondent), the number of occurred emotions varied from 2 to 18 , with an average of 8 experienced emotions (7.81). The most intensely experienced emotions are enthusiasm, pride, happiness, hope, and joy, which occur with such intensity only for positive events. The emotions which prevail for the negative event of strategic planning are frustration, disappointment, sadness and hope. The events of strategic planning appraised as neutral, do not provoke high intensity emotions (except for sadness when appraised from the perspective of the organization), as averages point to weak emotion intensities. The data presented in Table 5 confirms that the event of strategic planning is a trigger of both positive and negative emotions $\left(H_{2 b}\right)$.

The number of emotion occurrences is lower for the strategic planning event than for problem-solving. In comparison to problem-solving (Table 1), in strategic planning the respondents show smaller average number of experienced emotions with higher variability (Table 5). This observation is confirmed by related samples Wilcoxon signed rank test, used for the repeated measures on the same subject under different conditions (in this case, different events of strategic decision-making). There are statistically significant differences $(p<0.05)$ in the intensities of hate, contempt, fear, frustration, disappointment, disgust, hope, surprise and sadness given the type of strategic decision-making event. For each case in the observed differences, the average intensity of experienced emotion is higher for the event of strategic problem-solving. Average intensities of experienced enthusiasm and happiness are higher for the event of strategic planning (while average intensities for other emotions are higher for strategic problem-solving event), but those differences are not statistically significant. That means that $H_{6}$ can be rejected for the stated emotions, which is in line with the presumption that the two strategic decision-making events will trigger different levels of emotions. Thus, we may conclude that the event of strategic problemsolving provokes the higher intensities of hate, contempt, fear, frustration, disappointment, disgust, sadness, surprise, and hope than the event of strategic planning.

While differences in the emotions expressed in the event of strategic planning seem to be evident from the descriptives, hypothesis testing is due for confirmation $\left(\mathrm{H}_{3 b}\right)$.

Similarly, as for the event of solving a strategic problem, non-parametric tests show that there are statistically significant differences between emotion intensities given the event appraisal, both from the perspective of the organization and from a personal perspective ( $H_{3 b}$ is rejected). If we observe only the differences that arise at $1 \%$ statistical significance, for event appraisal from the perspective of the organization they occur for: enthusiasm, disappointment, disgust, happiness, joy, pride, and sadness; while for event appraisal from a personal perspective they occur for: anger, enthusiasm, disappointment, shame, disgust, happiness, joy, pride, and sadness (Table 6). 
Table 5. Descriptive statistics of intensity of experienced emotions during an event of strategic planning.

\begin{tabular}{|c|c|c|c|c|c|c|c|c|c|c|c|c|c|c|c|c|c|c|c|}
\hline \multirow{3}{*}{ Emotions } & \multirow{2}{*}{\multicolumn{7}{|c|}{$\begin{array}{l}\text { Experienced Emotions Related to the Event of } \\
\text { Strategic Planning }\end{array}$}} & \multicolumn{6}{|c|}{ Event Appraisal from the Organizational Perspective } & \multicolumn{6}{|c|}{ Event Appraisal from a Personal Perspective } \\
\hline & & & & & & & & \multicolumn{2}{|c|}{ Negative, $\mathrm{n}=3$} & \multicolumn{2}{|c|}{ Neutral, $n=3$} & \multicolumn{2}{|c|}{ Positive, $n=42$} & \multicolumn{2}{|c|}{ Negative, $\mathrm{n}=5$} & \multicolumn{2}{|c|}{ Neutral, $\mathrm{n}=3$} & \multicolumn{2}{|c|}{ Positive, $n=40$} \\
\hline & Min & Max & $\mathbf{o}$ & $\mu$ & $\mathbf{s}$ & Sk & $\mathbf{K}$ & $\mu$ & $\mathbf{s}$ & $\mu$ & $\mathbf{s}$ & $\mu$ & $\mathbf{s}$ & $\mu$ & s & $\mu$ & $\mathbf{s}$ & $\mu$ & $\mathbf{s}$ \\
\hline anger & 0 & 100 & 12 & 11.04 & 24.091 & 2.353 & 4.874 & 40.00 & 36.06 & 10.00 & 11.136 & 9.05 & 23.029 & 42.20 & 36.91 & 9.67 & 11.240 & 7.25 & 20.344 \\
\hline contempt & 0 & 73 & 5 & 3.38 & 13.653 & 4.611 & 20.832 & 1.00 & 1.73 & 0.33 & 0.577 & 3.76 & 14.570 & 15.20 & 32.34 & 5.00 & 7.810 & 1.78 & 9.670 \\
\hline enthusiasm & 0 & 100 & 44 & 66.69 & 33.695 & -0.787 & -0.598 & 6.33 & 10.97 & 26.00 & 42.462 & 73.90 & 27.689 & 11.00 & 16.22 & 17.33 & 18.339 & 77.35 & 24.950 \\
\hline envy & 0 & 63 & 5 & 2.17 & 9.388 & 6.092 & 39.492 & 0.00 & 0.00 & 0.00 & 0.000 & 2.48 & 10.013 & 1.80 & 4.02 & 4.67 & 8.083 & 2.03 & 10.035 \\
\hline fear & 0 & 99 & 22 & 15.69 & 24.691 & 1.841 & 2.964 & 0.00 & 0.00 & 15.33 & 26.558 & 16.83 & 25.398 & 17.60 & 39.35 & 20.33 & 23.459 & 15.10 & 23.348 \\
\hline frustration & 0 & 93 & 21 & 18.77 & 27.931 & 1.414 & 0.768 & 50.00 & 43.59 & 31.67 & 19.604 & 15.62 & 26.252 & 50.00 & 41.36 & 17.00 & 17.000 & 15.00 & 24.699 \\
\hline disappointment & 0 & 100 & 17 & 16.06 & 27.057 & 1.709 & 1.926 & 74.33 & 23.16 & 46.33 & 26.083 & 9.74 & 20.577 & 70.20 & 24.25 & 17.33 & 15.144 & 9.20 & 19.647 \\
\hline shame & 0 & 60 & 5 & 2.67 & 10.151 & 4.601 & 23.035 & 10.67 & 16.77 & 0.00 & 0.000 & 2.29 & 9.952 & 9.20 & 13.01 & 7.33 & 12.702 & 1.50 & 9.487 \\
\hline disgust & 0 & 86 & 6 & 3.96 & 15.083 & 4.605 & 21.975 & 5.33 & 8.39 & 4.33 & 7.506 & 3.83 & 15.951 & 23.00 & 35.87 & 5.67 & 9.815 & 1.45 & 9.171 \\
\hline happiness & 0 & 100 & 44 & 58.31 & 34.907 & -0.343 & -1.189 & 5.33 & 9.24 & 35.67 & 37.634 & 63.71 & 32.415 & 5.40 & 7.60 & 16.33 & 13.650 & 68.08 & 29.337 \\
\hline hate & 0 & 58 & 4 & 1.85 & 8.632 & 6.175 & 40.170 & 0.00 & 0.00 & 0.00 & 0.000 & 2.12 & 9.211 & 2.20 & 4.92 & 4.67 & 7.234 & 1.60 & 9.162 \\
\hline hope & 0 & 100 & 44 & 60.94 & 32.231 & -0.485 & -0.681 & 50.67 & 50.01 & 25.00 & 43.301 & 64.24 & 29.395 & 37.80 & 41.62 & 8.00 & 7.211 & 67.80 & 27.187 \\
\hline jealousy & 0 & 58 & 6 & 2.21 & 8.836 & 5.710 & 35.437 & 0.00 & 0.00 & 0.00 & 0.000 & 2.52 & 9.418 & 1.80 & 4.02 & 5.67 & 9.815 & 2.00 & 9.301 \\
\hline joy & 0 & 100 & 41 & 51.85 & 34.825 & -0.084 & -1.167 & 0.00 & 0.00 & 24.33 & 25.027 & 57.52 & 32.782 & 4.40 & 9.84 & 20.67 & 10.693 & 60.13 & 31.814 \\
\hline love & 0 & 100 & 23 & 23.98 & 33.699 & 1.209 & 0.115 & 0.00 & 0.00 & 16.67 & 28.868 & 26.21 & 34.786 & 1.60 & 3.58 & 2.33 & 3.215 & 28.40 & 35.305 \\
\hline pride & 0 & 100 & 42 & 60.71 & 35.743 & -0.420 & -1.113 & 6.33 & 10.97 & 25.00 & 43.301 & 67.14 & 31.861 & 11.40 & 16.99 & 16.33 & 20.984 & 70.20 & 30.525 \\
\hline surprise & 0 & 100 & 23 & 17.92 & 25.771 & 1.507 & 1.486 & 23.33 & 40.41 & 16.67 & 28.868 & 17.62 & 25.271 & 29.00 & 39.75 & 4.33 & 7.506 & 17.55 & 24.603 \\
\hline sadness & 0 & 100 & 11 & 11.63 & 25.850 & 2.219 & 3.846 & 57.00 & 50.76 & 50.33 & 27.934 & 5.62 & 17.465 & 62.80 & 38.36 & 23.67 & 25.697 & 4.33 & 14.797 \\
\hline
\end{tabular}

Notes: o stands for num

Notes: o stands for numple kurtosis; $\mathrm{n}=48$.
samplo 
Table 6. Non-parametric tests of differences in expressed emotions given the strategic planning event appraisal.

\begin{tabular}{ccc}
\hline Emotions & $\begin{array}{c}\text { Event Appraisal from the } \\
\text { Perspective of the Organization }\end{array}$ & $\begin{array}{c}\text { Event Appraisal from a } \\
\text { Personal Perspective }\end{array}$ \\
\hline Anger & $5.355^{*}$ & $11.327^{* * *}$ \\
Contempt & $0.730^{* *}$ & $7.272^{* *}$ \\
Enthusiasm & $10.830^{* * *}$ & $17.236^{* * *}$ \\
Envy & $1.137^{*}$ & $1.388^{-}$ \\
Fear & 2.260 & 0.855 \\
Frustration & $4.150^{* * *}$ & $4.281^{* *}$ \\
Disappointment & $14.967^{* * *}$ & $15.444^{* * *}$ \\
Shame & $10.220^{* *}$ & $16.131^{* * *}$ \\
Disgust & $8.516^{* * *}$ & $23.976^{* * *}$ \\
Happiness & $7.757^{* * *}$ & $15.922^{* * *}$ \\
Hate & $1.330^{* *}$ \\
Hope & 2.692 & $5.991^{* *}$ \\
Jealousy & 1.328 & $9.038^{* *}$ \\
Joy & $9.251^{* * *}$ & $1.007^{* *}$ \\
Love & $3.516^{* * *}$ & $13.246^{* * *}$ \\
Pride & $9.263^{* * *}$ & $3.386^{* *}$ \\
Surprise & $0.182^{* * *}$ & $15.310^{* * *}$ \\
Sadness & $17.214^{* * *}$ & $0.952^{* * *}$
\end{tabular}

Notes: reported values are Chi-square results of Kruskal Wallis tests; $\mathrm{df}=2 ; \mathrm{n}=48$; statistically significant differences at $10 \%, 5 \%$, and $1 \%$ level are denoted $* * *$ and ${ }^{* * *}$, respectively.

The distinction appears for anger and shame. While the distinction in anger can be related to solving a strategic problem, shame differs given the differences in two event appraisals. At this point, we can assume that the intensity of anger is the best indicator of the difference between event appraisals from a personal and organizational perspective.

This makes sense, as the anger is triggered by circumstances and external (someone else's) action, which can arise from event characteristics: level of involvement and perception of control.

Enthusiasm, happiness, hope, joy, and pride positively correlate to event assessment from a personal perspective, while anger, contempt, frustration, disappointment, shame, disgust, and sadness negatively correlate to event assessment (Table $7, \mathrm{H}_{4 b}$ is rejected). From the perspective of the organization, enthusiasm, happiness, joy, and pride positively correlate with the event appraisal, while anger, frustration, disappointment, shame, disgust and sadness correlate negatively. Higher intensities of dominantly positive emotions lead to positive event appraisal, while higher intensities of dominantly negative emotions lead to negative event appraisal. Contempt and hope appear statistically significant only for the event appraisal from a personal perspective, pointing out that the difference in intensity of those emotions may relate also to the difference in the event appraisal from different perspectives.

When observing partial correlations of emotions that occur for the event of strategic planning (Table 8), some similarities to the partial correlation analysis of emotion intensity for the event of solving a strategic problem may be noticed-emotions in the first group (E1-E7) mostly corelate positively amongst themselves, as well as emotions in the second group (E8-E18). 
However, there are also some differences. First, the observed correlations between emotions in both groups reveal a few positive and strong correlations. Second, there are fewer positively correlated emotions of positive valence with emotions of negative valence. The exceptions are surprise and love, which confirms $\mathrm{H}_{5}$ and the coexistence of emotions of different dominant valence (namely, $H_{5 b}$ is rejected). The intensity of experienced surprise positively correlates with fear, frustration, disappointment, hate, jealousy, and sadness (while there are no statistically significant correlations to emotions E1-E7)-and that may indicate that respondents experience surprise as a dominantly negative valence emotion and not as emotion of positive valence [20,55]. Third, several negative correlations occur between emotions from the first and second.

Fewer positive correlations between emotions of dominantly positive with emotions of dominantly negative valence leads to conclusion that the separation between the emotions of dominantly positive and negative valence is much clearer for the event of strategic planning than for event of solving a strategic problem. In addition, there are more negative correlations between the intensities of emotions from the two groups. Nevertheless, the findings still allow the coexistence of dominantly positive and negative valence without the relationship between their intensities. Observed in combination, findings lead to conclusion that the event of strategic planning is less emotionally ambivalent for examined HR managers than the event of solving a strategic problem, regardless of the event appraisal.

Table 7. Non-parametric correlation of intensity of emotions with strategic planning event appraisal.

\begin{tabular}{ccc}
\hline Emotions & $\begin{array}{c}\text { Event Appraisal from a } \\
\text { Personal Perspective }\end{array}$ & $\begin{array}{c}\text { Event Appraisal from the } \\
\text { Perspective of the Organization }\end{array}$ \\
\hline Anger & $-0.454^{* * *}$ & $-0.316^{* *}$ \\
Contempt & $-0.350^{* *}$ & -0.121 \\
Enthusiasm & $0.513^{* * *}$ & $0.400^{* * *}$ \\
Envy & -0.131 & 0.148 \\
Fear & $0.033^{*}$ & 0.163 \\
Frustration & $-0.246^{*}$ & $-0.264^{* *}$ \\
Disappointment & $-0.490^{* * *}$ & $-0.514^{* * *}$ \\
Shame & $-0.550^{* * *}$ & $-0.289^{* *}$ \\
Disgust & $-0.649^{* * *}$ & $-0.386^{* * *}$ \\
Happiness & $0.491^{* * *}$ & $0.328^{* * *}$ \\
Hate & $-0.227^{* * * 161^{*}}$ & $0.168^{*}$ \\
Hope & $0.334^{* * *}$ & $0.168^{* * 1}$ \\
Jealousy & $-0.103^{* * *}$ & $0.159^{* * *}$ \\
Joy & $0.454^{* *}$ & $0.221^{*}$ \\
Love & $0.228^{* *}$ & $0.369^{* * *}$ \\
Pride & $0.486^{* * *}$ & $0.051^{* *}$ \\
Surprise & $0.056^{* * *}$ & $-0.558^{* * *}$ \\
Sadness & $-0.565^{* * *}$ &
\end{tabular}

Notes: Kendall Tau-b correlation coefficients are reported; $\mathrm{n}=48$; statistically significant differences at $10 \%, 5 \%$ and $1 \%$ level are denoted $*, * *$ and $* * *$, respectively. 
Table 8. Non-parametric partial correlations of intensity of emotions experience with event appraisal from the perspective of organization as control variable.

\begin{tabular}{|c|c|c|c|c|c|c|c|c|c|c|c|c|c|c|c|c|c|c|}
\hline & E1 & E2 & E3 & E4 & E5 & E6 & E7 & E8 & E9 & E10 & E11 & E12 & E13 & E14 & E15 & E16 & E17 & E18 \\
\hline E1 & & $0.652 * * *$ & $0.434^{* * * *}$ & $0.629 * * *$ & $0.534 * * *$ & $0.782 * * *$ & & & & & $-0.282 * *$ & & & & & & & \\
\hline E2 & $0.652 * * *$ & & $0.524 * * *$ & $0.765 * * *$ & $0.564^{* * *}$ & $0.692 * * *$ & & & & & -0.261 ** & & & & & & & \\
\hline E3 & $0.434^{* * *}$ & $0.524 * * *$ & & $0.507^{* * *}$ & $0.394 * * *$ & $0.469^{* * *}$ & & & -0.226 * & & & & & & & & & \\
\hline $\mathrm{E} 4$ & $0.629^{* * *}$ & $0.765 * * *$ & $0.507^{* * *}$ & & $0.538^{* * *}$ & $0.571^{* * *}$ & & & & & & & & & & & & \\
\hline E5 & $0.534^{* * *}$ & $0.564 * * *$ & $0.394^{* * *}$ & $0.538 * * *$ & & $0.527 * * *$ & & & & & & & & & $0.356^{* * *}$ & & & \\
\hline E6 & $0.782 * * *$ & $0.692 * * *$ & $0.469^{* * *}$ & $0.571^{* * *}$ & $0.527^{* * *}$ & & & & & $-0.248 *$ & -0.338 ** & & & & & & & \\
\hline E7 & & & & & & & & & & $0.326^{* *}$ & 0.339 ** & $0.365^{* * *}$ & & & $0.231 *$ & $0.264 *$ & $0.357 * * *$ & \\
\hline E8 & & & & & & & & & $0.519^{* * * *}$ & $0.432 * * *$ & & $0.419 * * *$ & 0.237 * & $0.240 *$ & 0.284 ** & 0.236 * & $0.350 * * *$ & 0.247 * \\
\hline E9 & & & & & & & & $0.519^{* * *}$ & & $0.473 * * *$ & $0.240 *$ & 0.390 *** & & $0.539 * * *$ & $0.464^{* * * *}$ & $0.424^{* * * *}$ & $0.316^{* *}$ & \\
\hline E10 & & & -0.226 * & & & & & $0.432 * * *$ & $0.473^{* * * *}$ & & & 0.286 ** & $0.305^{* *}$ & $0.537^{* * *}$ & $0.510^{* * *}$ & $0.494^{* * *}$ & $0.694^{* * * *}$ & $0.335 * *$ \\
\hline E11 & & & & & & -0.248 * & 0.326 ** & & $0.240 *$ & & & $0.625 * * *$ & $0.393^{* * *}$ & & & & $0.344^{* *}$ & $0.376^{* * *}$ \\
\hline E12 & $-0.282 * *$ & $-0.261^{* *}$ & & & & -0.338 ** & 0.339 ** & $0.419 * * *$ & $0.390^{* * * *}$ & 0.286 ** & $0.625^{* * *}$ & & $0.584^{* * *}$ & & & & & $0.497^{* * *}$ \\
\hline E13 & & & & & & & $0.365 * * *$ & $0.237^{*}$ & & $0.305^{* *}$ & $0.393^{* * *}$ & $0.584^{* * *}$ & & $0.393 * *$ & $0.432 * * *$ & & & $0.614^{* * *}$ \\
\hline E14 & & & & & & & & 0.240 * & $0.539 * * *$ & $0.537^{* * *}$ & & & $0.393 * *$ & & $0.877^{* * *}$ & $0.458 * * *$ & $0.510 * * *$ & $0.407 * * *$ \\
\hline E15 & & & & & & & & $0.284^{* *}$ & $0.464 * * *$ & $0.510 * * *$ & & & 0.432 *** & $0.877^{* * * *}$ & & $0.403^{* * *}$ & $0.484 * * *$ & 0.460 *** \\
\hline E16 & & & & & $0.356^{* * *}$ & & $0.231 *$ & 0.236 * & $0.424 * * *$ & $0.494 * * *$ & & & & $0.458^{* * *}$ & $0.403 * * *$ & & $0.304^{* *}$ & \\
\hline E17 & & & & & & & $0.264^{*}$ & $\underset{* * *}{0.350}$ & $0.316^{* *}$ & $0.694^{* * *}$ & $0.344^{* *}$ & & & $0.510^{* * *}$ & $0.484^{* * *}$ & $0.304^{* *}$ & & $0.392^{* * *}$ \\
\hline E18 & & & & & & & $0.357^{* * *}$ & $0.247 *$ & & $0.335 * *$ & $0.376^{* * *}$ & $0.497 * * *$ & $0.614^{* * *}$ & $0.407^{* * *}$ & $0.460^{* * *}$ & & $0.392 * * *$ & \\
\hline
\end{tabular}

Notes: reported values are partial correlation coefficients; E1—enthusiasm, E2-happiness, E3-hope, E4-joy, E5-love, E6-pride, E7—surprise, E8—anger, E9—contempt, E10—envy,

E11-fear, E12-frustration, E13-disappointment, E14—shame, E15-disgust, E16-hate, E17-jealousy, E18—sadness; statistical significance levels of 10\%, 5\% and 1\% are denoted *,** and ***, respectively 


\subsection{Job Satisfaction}

Affective events theory suggests that work-related events influence employees' job satisfaction. While the theory primarily focuses on the aggregation of hassles and uplifts that ultimately lead to a certain level of satisfaction, here we examine the relationship of only two separate events to job satisfaction. The above represents a limitation of possible interpretation, but it is worth examining the relationship given that the events' importance, consequences, and experienced emotions may relate to overall job satisfaction.

Table 9 shows that strategic problem-solving event moderately and positively correlates to job satisfaction (both from a cognitive and affective perspective) at $1 \%$ level of statistical significance. Statistically significant correlation does not occur for the event of strategic planning. The hypotheses $H_{7 a}$ and $H_{7 b}$ should be rejected, as results show that only the appraisal of strategic problem-solving correlates to job satisfaction. The lack of the statistically significant correlation between appraisals of strategic planning events to job satisfaction does not allow rejection of $H_{7 c}$ and $H_{7 d}$. That means that $H_{7}$ is only partially proven and is valid for the event of strategic problem-solving. This points out that the events of strategic problem-solving are a better indicator of overall job satisfaction than the events of strategic planning. Given the moderate correlation, it must not be overlooked that there are other factors that shape job satisfaction but are not accounted for in this analysis.

Table 9. Relationship between job satisfaction and event appraisal.

\begin{tabular}{ccccc}
\hline $\begin{array}{c}\text { Job } \\
\text { Satisfaction/Event } \\
\text { Appraisal }\end{array}$ & $\begin{array}{c}\text { Strategic } \\
\text { Problem-Solving Event } \\
\text { Appraisal from a } \\
\text { Personal Perspective }\end{array}$ & $\begin{array}{c}\text { Problem-Solving Event } \\
\text { Appraisal from } \\
\text { Organizational } \\
\text { Perspective }\end{array}$ & $\begin{array}{c}\text { Strategic Planning } \\
\text { Event Appraisal from } \\
\text { a Personal Perspective }\end{array}$ & $\begin{array}{c}\text { Strategic Planning } \\
\text { Event Appraisal from } \\
\text { Organizational } \\
\text { Perspective }\end{array}$ \\
\hline $\begin{array}{c}\text { Cognitive aspect of } \\
\text { job satisfaction } \\
\begin{array}{c}\text { Affective aspect of } \\
\text { job satisfaction }\end{array}\end{array}$ & $0.461^{* * *}$ & $0.299 * *$ & 0.203 & 0.174 \\
\hline
\end{tabular}

Notes: Kendall Tau-b correlation coefficients are reported; $\mathrm{n}=45$; statistically significant differences at $5 \%$ and $1 \%$ level are denoted, ${ }^{* *}$ and ***, respectively.

It can also be noticed that the correlation coefficients are higher for the relationship between job satisfaction and problem-solving event appraisal from a personal perspective, as well as the correlation coefficients between job satisfaction from affective perspective and both strategic problem-solving appraisals. This leads to conclude that the event appraisal from a personal perspective, as well as the emotional aspect lead to stronger (however, still moderate) relationship between the event appraisal and job satisfaction. Given this finding, it makes sense to examine the relationship between the emotions experienced during events and job satisfaction. In order to do so, but to account for the event appraisal, the data were separated given the event appraisals for both strategic events. Due to the size of the subgroups, the correlation analysis could have been conducted only for the subgroup where the event of problem-solving was appraised either negatively or positively from both personal and organizational perspective; and only for positively appraised event of strategic planning from both personal and organizational perspective.

Given the revealed statistically significant correlation coefficients (Table 10), it can be noticed that different emotions appear significant in the relationship between job satisfaction to different events and different event appraisal $\left(H_{8}\right)$. Negatively experienced event of strategic problem-solving reveals moderate to strong relationship of contempt, enthusiasm, fear, hope and joy to cognitive aspect of job satisfaction; and moderate relationship of enthusiasm, fear, shame, disgust, hope, and sadness to affective aspect of job satisfaction. In case of negatively appraised event of problem-solving, for both cognitive and affective aspect of job satisfaction, enthusiasm, fear, hope, and joy play a role. The respondents who participated in a negatively perceived event of strategic problem-solving will probably 
show higher level of job satisfaction if they experienced enthusiasm, fear, hope, and joy at higher intensity, and contempt (for cognitive aspect) and disgust (for affective aspect) at lower intensity.

Table 10. Relationship between emotions and job satisfaction.

\begin{tabular}{|c|c|c|c|c|c|c|}
\hline \multirow[t]{2}{*}{ Emotions } & \multicolumn{2}{|c|}{$\begin{array}{l}\text { Negatively Appraised Event of } \\
\text { Problem-Solving from Both Personal and } \\
\text { Organizational Perspective, } n=7\end{array}$} & \multicolumn{2}{|c|}{$\begin{array}{c}\text { Positively Appraised Event of } \\
\text { Problem-Solving from Both Personal and } \\
\text { Organizational Perspective, } n=28\end{array}$} & \multicolumn{2}{|c|}{$\begin{array}{l}\text { Positively Appraised Event of Strategic } \\
\text { Planning from Both Personal and } \\
\text { Organizational Perspective, } n=35\end{array}$} \\
\hline & $\begin{array}{l}\text { Cognitive Aspect } \\
\text { of Job Satisfaction }\end{array}$ & $\begin{array}{c}\text { Affective Aspect of } \\
\text { Job Satisfaction }\end{array}$ & $\begin{array}{l}\text { Cognitive Aspect } \\
\text { of Job Satisfaction }\end{array}$ & $\begin{array}{l}\text { Affective Aspect of } \\
\text { Job Satisfaction }\end{array}$ & $\begin{array}{l}\text { Cognitive Aspect } \\
\text { of Job Satisfaction }\end{array}$ & $\begin{array}{c}\text { Affective Aspect of } \\
\text { Job Satisfaction }\end{array}$ \\
\hline \multicolumn{7}{|l|}{ Anger } \\
\hline Contempt & $-0.583 *$ & & & & & \\
\hline Enthusiasm & $0.657 *$ & $0.674^{*}$ & $0.291 *$ & & & \\
\hline \multicolumn{7}{|l|}{ Envy } \\
\hline Fear & 0.756 ** & $0.640 *$ & & & & \\
\hline Frustration & & & & & $-0.301 * *$ & $-0.333^{* *}$ \\
\hline Disappointment & & & & $-0.326^{* *}$ & $-0.317^{* *}$ & $-0.373^{* *}$ \\
\hline Shame & & $0.636^{*}$ & & & & \\
\hline Disgust & & $-0.607^{*}$ & & & & \\
\hline \multicolumn{7}{|l|}{ Happiness } \\
\hline \multicolumn{7}{|l|}{ Hate } \\
\hline Hope & $0.816^{* *}$ & $0.592 *$ & & & & \\
\hline \multicolumn{7}{|l|}{ Jealousy } \\
\hline Joy & 0.630 * & $0.640 *$ & & & & \\
\hline \multicolumn{7}{|l|}{ Love } \\
\hline \multicolumn{7}{|l|}{ Pride } \\
\hline \multicolumn{7}{|l|}{ Surprise } \\
\hline Sadness & & $0.607 *$ & $-0.496^{* * *}$ & $-0.402 * *$ & & \\
\hline
\end{tabular}

Notes: Kendall Tau-b correlation coefficients are reported; statistically significant differences at $10 \%, 5 \%$ and $1 \%$ level are denoted *,** and ***, respectively.

For a positively appraised event of strategic problem-solving, there is a weak and positive relationship between enthusiasm and cognitive aspect of job satisfaction (meaning that higher intensity of experienced enthusiasm relates to higher job satisfaction); and moderate and negative relationship between disappointment and affective aspect of job satisfaction (meaning that higher intensity of experienced disappointment relates to lower job satisfaction). With both cognitive and affective aspect of job satisfaction, sadness correlates negatively with moderate intensity, meaning that the job satisfaction will probably be lower if sadness is experienced at higher intensity.

For a positively appraised event of strategic planning, frustration and disappointment show moderate and negative relationship to cognitive and affective aspect of job satisfaction, meaning that experienced intensities of frustration and disappointment diminish job satisfaction.

Thus, both $\mathrm{H}_{8 a}$ and $\mathrm{H}_{8 b}$ can be rejected, confirming $\mathrm{H}_{8}$. It seems that the respondents who experienced the strategic event negatively, experience more distinct emotions which correlate to job satisfaction.

\section{Discussion and Conclusions}

Respondents were able to cognitively appraise events of strategic planning and problem-solving as positive, neutral, or negative. Given that a part of the respondents demonstrated the ability of such appraisal, it can be concluded that some respondents experienced such situations that enabled them to distinctly appraise the events from different perspectives: personal and organizational (although not in enough quantity to reveal statistically significant differences); which is in line with [17] and the affective events theory. The distinction between personal and organizational event appraisal reveals differences in experienced emotions, which was expected given the previous research of $[2,3,17]$. The intensity of anger is the best indicator of the difference between event appraisals from the personal and organizational perspective.

While [51] found happiness to be related to strategic problem-solving and enthusiasm to strategic planning, we find that enthusiasm is the most intensely experienced emotion during positively appraised strategic decision-making events, both strategic planning and 
strategic problem-solving. However, in case of negatively appraised events, the situation changes. Most intensely experienced emotion during negatively appraised strategic problem-solving is frustration and for strategic planning-disappointment. Those intensely experienced emotions may cross over to employees $[11-14,16]$ and consequently influence their motivation, performance, communication, and organization climate. Neutrally appraised strategic events reveal lower average intensities of emotions than positively and negatively appraised, as expected. The event of strategic problem-solving reveals emotions with higher levels of their average intensity in comparison to the event of strategic planning (except for enthusiasm and happiness), but those differences appear statistically significant for only seven emotions (of which, six are dominantly negative). That is partially in line with our assumption about emotion intensities given the event characteristics from the aspects of uncertainty and time pressure based on previous findings $[4,49,61]$. Nevertheless, both strategic events reveal the variety of involved emotions and the coexistence of -not just various emotions, but also-emotions of different dominant valence (which is confirmed by controlling for the event appraisals), which confirms previous qualitative research $[2,3,17]$.

The event of strategic planning does not correlate to more dominantly positive emotions than the event of solving a strategic problem, as we proposed, but reveals the coexistence and fewer correlations between dominantly positive and dominantly negative emotions (and more correlations of emotions within dominant valence). The opposite is true for the other event, which shows the higher emotional ambivalence in case of strategic problem-solving, indicating respondents' higher emotional turmoil than in the case of strategic planning event. This finding shows that in the events of strategic planning HR managers require additional emotional support, which should be provided through either formal or informal organizational structure.

Both cognitive and affective aspect of job satisfaction correlate to strategic problemsolving event appraisal, but not to strategic planning event appraisal. The revealed relationship between the experience of strategic problem-solving event and job satisfaction points out to requirement for engagement of additional forms of motivation (incentives or rewards) which might compensate for the effects of the strategic problem-solving event. While some emotions reveal statistically significant relationship to job satisfaction for all examined event appraisals, there is an indication that the respondents who experienced the strategic event negatively, experience more distinct emotions which correlate to job satisfaction. If that were the case with the employees, HR manager would be the one to deal with such issues. However, in this case, HR managers are the ones who require additional support, as experience of dominantly negative emotions and emotional turmoil may have consequences to health $[9,10]$ and lower job satisfaction may lead to search for other employment [1].

In the light of current events regarding the pandemic and consequential economic crisis, the role of manager's emotions in strategic decision-making is even more highlighted. Nowadays, business environment provokes more strategic problem-solving events, whichgiven the findings - present emotionally turbulent events and relate to job satisfaction. Hence, the question of managers' emotions becomes ever more current, because its consequences affect both the managers (i.e., their health and job satisfaction) and the organization (i.e., emotion crossover, communication, performance, strategy implementation [11-17]) and consequently - directly or indirectly, the organizational sustainability [18-22]. While this paper does not prove direct relationship of emotions in strategic decision-making to different aspects of organization sustainability, given the previous research, the theoretical and contextual deduction of such relationship is plausible [20-22].

Dess et al. [39] definition of problem-solving activities undoubtedly shows a close connection between problem-solving and strategic planning. Namely, digital technologies and the Internet enable faster, more accurate and comprehensive addressing of customers' needs and requirements, which are necessary prerequisites for solving current and future strategic problems, always through a strategic medium- and long-term plans. Furthermore, 
according to [35], every intended strategy will outgrow itself and transform into the realized one which will further require new problem-solving and adjustment of strategic plans. Both, especially due to turbulent changes, will involve the emotions of decision-makers.

Additional (unexpected) observations from the data direct the attention to hope and surprise. In the event of strategic problem-solving, hope is experienced in at least moderate intensity regardless of the event appraisal, suggesting that there really is always hope (as the saying goes). However, that is not true for the event of strategic planning, as hope appears frequently, but in lower intensity.

Limitations of the study are several. The applied research design examines occurrence and intensities of emotions in the events of strategic decision-making. This research does not examine the relationship of those emotions with the specific triggers within the events or the outcomes (besides the job satisfaction as a part of the affective events theory framework). While due diligence was paid to the questionnaire assembling and its distribution, data are based on self-reported data and recollection of the event and emotions, which may cause measurement error. Additional limitation is the scarcity of the previous research dealing with managers' emotions in strategic events, from which arises the limited possibility for results comparison. Also, a sample is relatively small and although a part of the findings is in line with available previous research, the results should be validated in the future research by inclusion of respondents who are working as HR managers and are not necessarily registered in Human Resources Development Community at Croatian Chamber of Commerce. Also, the examination of emotions of all managers (especially in top management) in the events of strategic decision-making is preferable. While the limitations of the study narrow the interpretation and possibility for generalization, they also suggest possibilities for further research. The extension of research framework to examination of emotion relationship to the triggers, outcomes/solutions and following implementation of strategic solution would additionally improve the knowledge of the role of emotions in strategic decision-making and organizational sustainability.

Author Contributions: Funding acquisition, M.G.B., K.K.; conceptualization, M.G.B., K.K.; methodology, M.G.B., K.K.; project administration, M.G.B.; investigation, M.G.B.; formal analysis, K.K.; writing—original draft preparation, K.K.; writing—review and editing, M.G.B., K.K. All authors have read and agreed to the published version of the manuscript.

Funding: This research and the APC was funded by "The role of emotions in strategic decisionmaking"-internal project at Faculty of Economics and tourism "Dr. Mijo Mirković" Pula.

Institutional Review Board Statement: Research Ethics Assessment Committee at Juraj Dobrila University of Pula gave their positive opinion on the research design "The role of emotions in strategic decision-making" and approved the questionnaire with the decision from 14 November 2019. The instruction for obtaining informed consent is stated at the first page of the questionnaire. The confidentiality of information on the identity of participants in the research is guaranteed. The questionnaires will be located on the online platform. Upon completion of data collection, the aggregated data will be stored on the personal computers of the researcher, protected by a password. Only researchers are allowed access to the data. If the findings of this research are made public, the data will be presented exclusively at the sample level and individual responses will not be published. The risk of a research procedure is minimal, i.e., that in which the degree of possible damage, discomfort or injury that the procedure will cause less than or equal to that to which the participants are exposed in performing daily activities.

Informed Consent Statement: Informed consent was obtained from all subjects involved in the study.

Data Availability Statement: The data presented in this study are available for review purposes on request from the corresponding author. The data are not publicly available due to the restriction by the Statement.

Acknowledgments: We thank the respondents for their voluntary participation. We are deeply grateful to Human Resources Development Community at the Croatian Chamber of Commerce for the help in questionnaire distribution. 
Conflicts of Interest: The authors declare no conflict of interest. The funders had no role in the design of the study; in the collection, analyses, or interpretation of data; in the writing of the manuscript, or in the decision to publish the results.

\section{Appendix A}

The questionnaire.

This questionnaire is used to conduct empirical research whose purpose is to explore the role of emotions in strategic decision-making, which is divided into two aspects: strategic planning and strategic problem-solving. The study involves the heads of departments of human resources in companies in the Republic of Croatia. The obtained data will be used only as a group of data for statistical processing and will not be analyzed at the level of individual or enterprise. With your answers, you contribute to the knowledge about the connection between an individual's emotions and their involvement in aspects of strategic decision-making.

The questionnaire also contains some questions about general demographic data; however, your name is not asked anywhere in the questionnaire. We also guarantee anonymity by not collecting IP addresses. Please answer the questions as spontaneously and honestly as possible. Kindly answer every question.

If you continue completing the questionnaire, you confirm that you have been informed about the research and that you agree to participate in it.

- I agree

- I disagree

1. Section: Exploring the role of emotions in strategic decision-making: Strategic problem-solving.

Describe an event that shows that you have been involved in solving problems with a strategic significance in the company in which you are employed in the period from 2017 to now. Please include the symptoms of the problem, the decision and its consequences (if known) in the description of the event.

Is this event for you:

- positive

- neutral

- negative

Is this event for the company:

- positive

- neutral

- $\quad$ negative

Assess how much each of these emotions relate to the previously described event. If a particular emotion does not relate to the described event, confirm zero percent $(0 \%)$ on the scale.

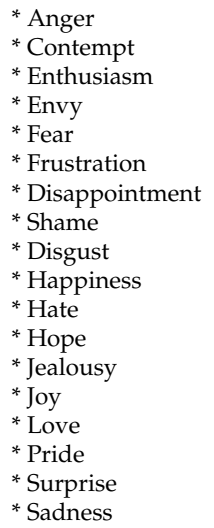

$\begin{array}{ll}0 \% \text { not at all } & 100 \% \text { completely } \\ 0 \% \text { not at all } & 100 \% \text { completely } \\ 0 \% \text { not at all } & 100 \% \text { completely } \\ 0 \% \text { not at all } & 100 \% \text { completely } \\ 0 \% \text { not at all } & 100 \% \text { completely } \\ 0 \% \text { not at all } & 100 \% \text { completely } \\ 0 \% \text { not at all } & 100 \% \text { completely } \\ 0 \% \text { not at all } & 100 \% \text { completely } \\ 0 \% \text { not at all } & 100 \% \text { completely } \\ 0 \% \text { not at all } & 100 \% \text { completely } \\ 0 \% \text { not at all } & 100 \% \text { completely } \\ 0 \% \text { not at all } & 100 \% \text { completely } \\ 0 \% \text { not at all } & 100 \% \text { completely } \\ 0 \% \text { not at all } & 100 \% \text { completely } \\ 0 \% \text { not at all } & 100 \% \text { completely } \\ 0 \% \text { not at all } & 100 \% \text { completely } \\ 0 \% \text { not at all } & 100 \% \text { completely } \\ 0 \% \text { not at all } & 100 \% \text { completely }\end{array}$

2. Section: Exploring the role of emotions in strategic decision-making: Strategic planning. 
Describe an event that shows that you were involved in crafting/formulating the strategy in the period from 2017 to now in the company in which you are employed. Please include the reasons, the decision and its consequences (if known) in the description of the event.

Is this event for you:

- positive

- neutral

- negative

Is this event for the company:

- positive

- neutral

- negative

Assess how much each of these emotions relate to the previously described event. If a particular emotion does not relate to the described event, confirm zero percent $(0 \%)$ on the scale.
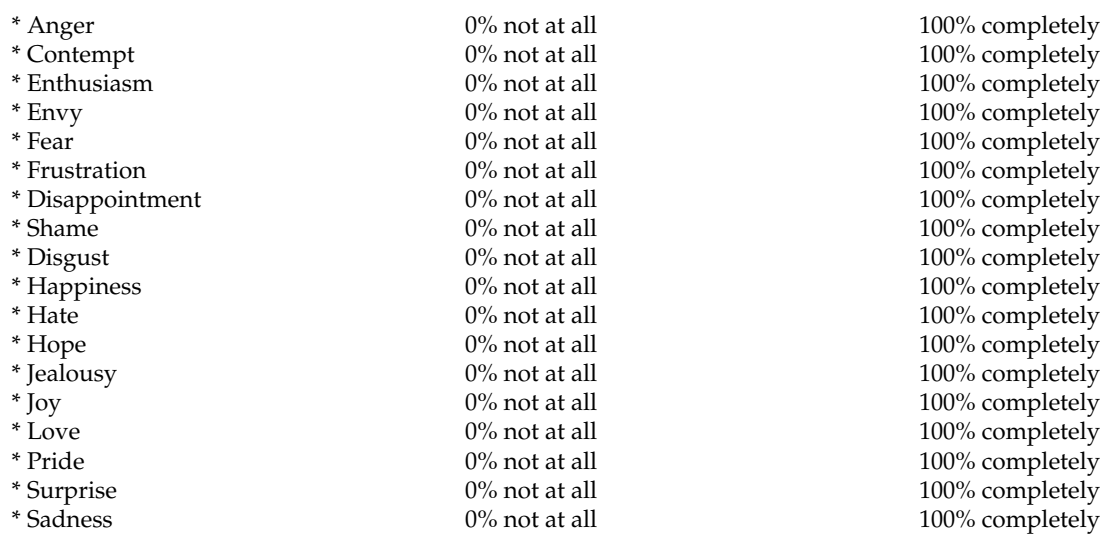

3. Section: Job satisfaction.

Please select one of the following statements which best describes your job satisfaction:

- $\quad$ I am satisfied with my job because positive events prevail.

- I am neither satisfied nor dissatisfied with my job because there are equally positive and negative events.

- I am dissatisfied with my job because negative events prevail.

Please select one of the following statements that best describes your job satisfaction:

- I am satisfied with my job because I often feel good.

- I am neither satisfied nor dissatisfied because I feel equally good and bad doing my job.

- I am dissatisfied with my job because I often feel bad.

4. Section: Socio-demographic characteristics of respondents and organization characteristics. Year of birth

(please enter only the number, for example: 1975)

\section{Gender}

Highest acquired title or education level

Field in which the qualification or title was acquired:

Total work experience:

(Please enter only the number, for example: 20)

Work experience in managerial positions:

(please enter only the number, for example: 10)

Specify the organization type

- $\quad$ profit organization 
- government institution, regional and local government and self-government units or a government agency

- public interest entities

- non-profit organization

If your organization is subject to profit accounting, please answer following questions. According to the Accounting Act of the Republic of Croatia, the company you are employed in is:

- Micro

- Small

- Medium

- Big

How many employees annually, on average, has the company where you are employed in:

- $<10$

- $11-50$

- $51-250$

- $\quad>251$

Note: originally, the questionnaire was assembled, and survey was conducted in Croatian language.

\section{References}

1. Rofcanin, Y.; Kiefer, T.; Strauss, K. What seals the I-deal? Exploring the role of employees' behaviours and managers' emotions. J. Occup. Organ. Psychol. 2017, 90, 203-224. [CrossRef]

2. Kiefer, T. Understanding the emotional experience of organizational change: Evidence from a merger. Adv. Dev. Hum. Resour. 2002, 4, 39-61. [CrossRef]

3. Hassett, M.E.; Reynolds, N.S.; Sandberg, B. The emotions of top managers and key persons in cross-border M\&As: Evidence from a longitudinal case study. Int. Bus. Rev. 2018, 27, 737-754. [CrossRef]

4. Neumann, F. Antecedents and effects of emotions in strategic decision-making: A literature review and conceptual model. Manag. Rev. Q. 2017, 67, 175-200. [CrossRef]

5. Ashkanasy, N.M.; Troth, A.C.; Lawrence, S.A.; Jordan, P.J. Emotions and emotional regulation in HRM: A multi-level perspective. In Research in Personnel and Human Resources Management; Emerald Publishing Limited: Bingley, UK, 2017. [CrossRef]

6. Ashkanasy, N.M.; Dorris, A.D. Emotions in the workplace. Annu. Rev. Organ. Psychol. Organ. Behav. 2017, 4, 67-90. [CrossRef]

7. Wright, P.M.; McMahan, G.C. Theoretical perspectives for strategic human resource management. J. Manag. 1992, 18, 295-320. [CrossRef]

8. Connelly, S.; Torrence, B.S. The Relevance of Discrete Emotional Experiences for Human Resource Management: Connecting Positive and Negative Emotions to HRM. In Research in Personnel and Human Resources Management; Emerald Publishing Limited: Bingley, UK, 2018. [CrossRef]

9. Sinkovics, R.R.; Zagelmeyer, S.; Kusstatscher, V. Between merger and syndrome: The intermediary role of emotions in four cross-border M\&As. Int. Bus. Rev. 2011, 20, 27-47. [CrossRef]

10. Sankaran, S.; Okay, N.; Chroust, G.; Berg, M.E.; Karlsen, J.T. How project managers can encourage and develop positive emotions in project teams. Int. J. Manag. Proj. Bus. 2014, 7, 449-472. [CrossRef]

11. Zagenczyk, T.J;; Powell, E.E.; Scott, K.L. How exhausting? Emotion crossover in organizational social networks. J. Manag. Stud. 2020, 57, 1589-1609. [CrossRef]

12. Rhee, S.Y.; Park, H.; Bae, J. Network Structure of Affective Communication and Shared Emotion in Teams. Behav. Sci. 2020, 10, 159. [CrossRef]

13. Ashkanasy, N.M.; Daus, C.S. Emotion in the workplace: The new challenge for managers. Acad. Manag. Perspect. 2002, 16, 76-86. [CrossRef]

14. Zagelmeyer, S.; Sinkovics, R.R.; Sinkovics, N.; Kusstatscher, V. Exploring the link between management communication and emotions in mergers and acquisitions. Can. J. Adm. Sci. Rev. Can. Sci. 2018, 35, 93-106. [CrossRef]

15. Newcombe, M.J.; Ashkanasy, N.M. The role of affect and affective congruence in perceptions of leaders: An experimental study. Leadersh. Q. 2002, 13, 601-614. [CrossRef]

16. Ashkanasy, N.M. Emotion and performance. Hum. Perform. 2004, 17, 137-144. [CrossRef]

17. Huy, Q.N. How middle managers' group-focus emotions and social identities influence strategy implementation. Strateg. Manag. J. 2011, 32, 1387-1410. [CrossRef]

18. Montiel, I.; Antolin-Lopez, R.; Gallo, P.J. Emotions and sustainability: A literary genre-based framework for environmental sustainability management education. Acad. Manag. Learn. Educ. 2018, 17, 155-183. [CrossRef] 
19. Dzhengiz, T. A literature review of inter-organizational sustainability learning. Sustainability 2020, 12, 4876. [CrossRef]

20. Alola, U.V.; Avci, T.; Ozturen, A. Organization sustainability through human resource capital: The impacts of supervisor incivility and self-efficacy. Sustainability 2018, 10, 2610. [CrossRef]

21. Moslehpour, M.; Altantsetseg, P.; Mou, W.; Wong, W.-K. Organizational climate and work style: The missing links for sustainability of leadership and satisfied employees. Sustainability 2019, 11, 125. [CrossRef]

22. Di Fabio, A. The psychology of sustainability and sustainable development for well-being in organizations. Front. Psychol. 2017, 8, 1534. [CrossRef]

23. Pfister, H.R.; Böhm, G. The multiplicity of emotions: A framework of emotional functions in decision making. Judgm. Decis. Mak. 2008, 3, 5 .

24. Andrade, E.B.; Ariely, D. The enduring impact of transient emotions on decision making. Organ. Behav. Hum. Decis. Process. 2009, 109, 1-8. [CrossRef]

25. Jordan, P.; Troth, A.; Ashkanasy, N.; Humphrey, R. The antecedents and consequences of fear at work. In The Cambridge Handbook of Workplace Affect. Cambridge Handbooks in Psychology; Cambridge University Press: Cambridge, UK, 2020; pp. 402-413. [CrossRef]

26. Knezevic, B.; Milosevic, M.; Golubic, R.; Belosevic, L.; Russo, A.; Mustajbegovic, J. Work-related stress and work ability among Croatian university hospital midwives. Midwifery 2009, 27, 146-153. [CrossRef] [PubMed]

27. Idris, M.A.; Dollard, M.F. Psychosocial safety climate, work conditions, and emotions in the workplace: A Malaysian populationbased work stress study. Int. J. Stress Manag. 2011, 18, 324. [CrossRef]

28. Mahdi, S.; Ibrahim, M.; Armia, S. The Role of Negative Emotions on the Relationship of Job Stress and Counterproductive Work Behavior (Research on Public Senior High School Teachers). Int. J. Asian Soc. Sci. 2018, 8, 77-84. [CrossRef]

29. Eisenhardt, K.M.; Zbaracki, M.J. Strategic decision making. Strateg. Manag. J. 1992, 13. [CrossRef]

30. Johnson, G.; Scholes, K.; Whittington, R. Exploring Corporate Strategy. Text and Cases, 8th ed.; FT Prentice Hall, Pearson Education Limited: Harlow, UK, 2008.

31. Guarini, M.R.; Morano, P.; Sica, F. Historical School Buildings. A Multi-Criteria Approach for Urban Sustainable Projects. Sustainability 2020, 12, 1076. [CrossRef]

32. Guarini, M.R.; Morano, P.; Sica, F. Eco-system Services and Integrated Urban Planning. A Multi-criteria Assessment Framework for Ecosystem Urban Forestry Projects. In Values and Functions for Future Cities; Springer: Cham, Switzerland, 2020; pp. 201-216.

33. Schwenk, C.R. Cognitive simplification processes in strategic decision-making. Strateg. Manag. J. 1984, 5, 111-128. [CrossRef]

34. Lynch, R. Strategic Management; Pearson Education limited: Harlow, UK, 2015.

35. Kepczynski, R.; Jandhyala, R.; Sankaran, G.; Dimofte, A. Integrated Business Planning. How to Integrate Planning Processes, Organizational Structures and Capabilities, and Leverage SAP IBP Technology; Springer International Publishing AG: Cham, Switzerland, 2018 ; p. 2.

36. Day, G.S. Strategic Market Planning; West Publishing: St. Paul, MN, USA, 1984.

37. Mintzberg, H. The fall and rise of strategic planning. In Harvard Business Review; Harvard Business Publishing: Boston, MA, USA, 1994; pp. 107-114.

38. Lynch, R. Corporate Strategy; FT Prentice Hall Financial Times: Harlow, UK, 2006.

39. Dess, G.G.; Lumpkin, G.T.; Eisner, A.B.; McNamara, G.; Kim, B. Strategic Management. Creating Competitive Advantages; Global Edition; McGraw-Hill Irwin: New York, NY, USA, 2012.

40. Curein, J.; Slater, R. Quantitative Methods for Business Decisions; Thomson Learning: Mason, OH, USA, 2002.

41. Mintzberg, H.; Waters, J.A. Of strategies, deliberate and emergent. Strateg. Manag. J. 1985, 6, 257-272. [CrossRef]

42. Frijda, N.H. The laws of emotion. Am. Psychol. 1988, 43, 349-358. [CrossRef]

43. Elfenbein, H.A. Emotion in Organizations: A Review and Theoretical Integration. Acad. Manag. Ann. 2007, 1, 371-457. [CrossRef]

44. Csikszentmihalyi, M. Play and intrinsic rewards. J. Humanist. Psychol. 1975, 15, 41-63. [CrossRef]

45. Sandelands, L.E. The concept of work feeling. J. Theory Soc. Behav. 1988, 18, 357-437. [CrossRef]

46. Barrett, L.F. Variety is the spice of life: A psychological construction approach to understanding variability in emotion. Cogn. Emot. 2009, 23, 1284-1306. [CrossRef] [PubMed]

47. Ekman, P. Basic emotions. Handb. Cogn. Emot. 1999, 98, 16.

48. Scherer, K.R.; Shuman, V.; Fontaine, J.; Soriano Salinas, C. The GRID meets the Wheel: Assessing emotional feeling via self-report. In Components of Emotional Meaning: A Sourcebook; Oxford University Press: Oxford, UK, 2013. [CrossRef]

49. Schwartz, S.H.; Cieciuch, J.; Vecchione, M.; Davidov, E.; Fischer, R.; Beierlein, C.; Dirilen-Gumus, O. Refining the theory of basic individual values. J. Personal. Soc. Psychol. 2012, 103, 663. [CrossRef]

50. Solomon, R.C. Back to Basics: On the Very Idea of "Basic Emotions". J. Theory Soc. Behav. 2002, 32, 115-144. [CrossRef]

51. Basch, J.; Fisher, C.D. Affective job events-emotions matrix: A classification of job related events and emotions experienced in the workplace. In Emotions in the Workplace: Research, Theory and Practice; Quorum Books: Westport, CT, USA, 2000 ; pp. 36-48.

52. Robins, S.P.; Judge, T.A. Organizacijsko Ponašanje; MATE: Zagreb, Croatia, 2009.

53. Fisher, C.D. Emotions at Work: What do People Feel and How Should We Measure It? School of Business Discussion Papers Paper 63; Bond University: Queensland, Australia, 1997. [CrossRef]

54. Tran, V.; Páez, D.; Sánchez, F. Emotions and decision-making processes in management teams: A collective level analysis. J. Work Organ. Psychol. 2012, 28, 15-24. [CrossRef]

55. Sacharin, V.; Schlegel, K.; Scherer, K.R. Geneva Emotion Wheel Rating Study. 2012. Available online: https://www.unige.ch/ cisa/files/4514/6720/4016/Geneva_Emotion_Wheel_Rating_Study_Report_2012_08_11_2.0.pdf (accessed on 14 October 2019). 
56. Weiss, H.M.; Cropanzano, R. Affective Events Theory: A Theoretical Discussion of the Structure, Causes and Consequences of Affective Experiences at Work. In Research in Organizational Behavior: An Annual Series of Analytical Essays and Critical Reviews; Staw, B.M., Cummings, L.L., Eds.; Elsevier Science/JAI Press: New York, NY, USA, 1996; Volume 18, pp. 1-74.

57. Lazarus, R.S. Progress on a cognitive-motivational-relational theory of emotion. Am. Psychol. 1991, 46, 819. [CrossRef]

58. Raghunathan, R.; Pham, M.T. All negative moods are not equal: Motivational influences of anxiety and sadness on decision making. Organ. Behav. Hum. Decis. Process. 1991, 79, 56-77. [CrossRef]

59. Treffers, T.; Klarner, P.; Huy, Q.N. Emotions, time, and strategy: The effects of happiness and sadness on strategic decision-making under time constraints. Long Range Plan. 2020, 53, 101954. [CrossRef]

60. Louro, M.J.; Pieters, R.; Zeelenberg, M. Dynamics of multiple-goal pursuit. J. Pers. Soc. Psychol. 2007, 93, 174. [CrossRef] [PubMed]

61. Schwarz, N. Feelings as Information: Informational and Motivational Functions of Affective States; The Guilford Press: New York, NY, USA, 1990. [CrossRef]

62. Loewenstein, G.F.; Weber, E.U.; Hsee, C.K.; Welch, N. Risk as feelings. Psychol. Bull. 2001, 127, 267. [CrossRef] [PubMed]

63. Porac, J.F. The job satisfaction questionnaire as a cognitive event: First-and second-order processes in affective commentary. Res. Pers. Hum. Res. Manag. 1987, 5, 51-102.

64. Robinson, M.D.; Clore, G.L. Belief and feeling: Evidence for an accessibility model of emotional self-report. Psycholo. Bull. 2002, 128, 934. [CrossRef]

65. Watson, D.; Tellegen, A. Toward a consensual structure of mood. Psychol. Bull. 1985, 98, 219. [CrossRef]

66. Basch, J.; Fisher, C.D. Development and validation of measures of hassles and uplifts at work. In Annual Meeting of the Academy of Management; Bond University: New Orleans, LA, USA, 2004; Available online: https://www.researchgate.net/publication/2280 79348_Development_and_Validation_of_Measures_of_Hassles_and_Uplifts_at_Work (accessed on 14 October 2019).

67. Mignonac, K.; Herrbach, O. Linking work events, affective states, and attitudes: An empirical study of managers' emotions. J. Bus. Psychol. 2004, 19, 221-240. [CrossRef]

68. Jarvis, L.C. Feigned versus felt: Feigning behaviors and the dynamics of institutional logics. Acad. Manag. Rev. 2017, 42, 306-333. [CrossRef]

69. Barrett, L.F. Solving the emotion paradox: Categorization and the experience of emotion. Pers. Soc. Psychol. Rev. 2006, 10, 20-46. [CrossRef]

70. Desmet, P. Measuring emotion: Development and application of an instrument to measure emotional responses to products. In Funology; Springer: Dordrecht, The Netherlands, 2003; pp. 111-123. [CrossRef]

71. Scherer, K.R. What are emotions? And how can they be measured? Soc. Sci. Inf. 2005, 44, 695-729. [CrossRef]

72. Accounting Act NN 120/16, 116/18. Available online: https://www.zakon.hr/z/118/Zakon-o-ra\%C4\%8Dunovodstvu (accessed on 14 October 2019). 